\title{
Trophic strategies of unicellular plankton
}

\section{Chakraborty, Subhendu; Nielsen, Lasse Tor; Andersen, Ken Haste}

\section{Published in:}

American Naturalist

Link to article, DOI:

$10.1086 / 690764$

Publication date:

2017

Document Version

Peer reviewed version

Link back to DTU Orbit

Citation (APA):

Chakraborty, S., Nielsen, L. T., \& Andersen, K. H. (2017). Trophic strategies of unicellular plankton. American Naturalist, 189(4), E77-E90. https://doi.org/10.1086/690764

\section{General rights}

Copyright and moral rights for the publications made accessible in the public portal are retained by the authors and/or other copyright owners and it is a condition of accessing publications that users recognise and abide by the legal requirements associated with these rights.

- Users may download and print one copy of any publication from the public portal for the purpose of private study or research.

- You may not further distribute the material or use it for any profit-making activity or commercial gain

- You may freely distribute the URL identifying the publication in the public portal

If you believe that this document breaches copyright please contact us providing details, and we will remove access to the work immediately and investigate your claim 


\title{
Trophic strategies of unicellular plankton
}

Authors: Subhendu Chakraborty, Lasse Tor Nielsen and Ken H. Andersen

Affiliation:

VKR Centre for Ocean Life, National Institute of Aquatic Resources, Technical University of Denmark, Charlottenlund Slot, Jægersborg Allé, DK-2920

Charlottenlund, Denmark

E-mail addresses: Subhendu Chakraborty (subc@aqua.dtu.dk), Lasse Tor Nielsen (ltor@aqua.dtu.dk ), Ken H. Andersen (kha@ aqua.dtu.dk)

Keywords: plankton size, mixotrophy, trait based model, seasonal succession

Corresponding author: Subhendu Chakraborty, Centre for Ocean Life, National Institute of Aquatic Resources, Technical University of Denmark, Charlottenlund Slot, Jægersborg Allé, DK-2920 Charlottenlund, Denmark. E-mail: subc@aqua.dtu.dk

Manuscript type: Article

Elements of the manuscript: Abstract, Introduction, Model description, Model parameterization, Results, Discussion, Appendices, Figures.

\begin{abstract}
Unicellular plankton employ trophic strategies ranging from pure photoautotrophs over mixotrophy to obligate heterotrophs (phagotrophs), with cell sizes from $10^{-8}$ to 1 $\mu \mathrm{gC}$. A full understanding of how trophic strategy and cell size depend on resource environment and predation is lacking. To this end, we develop and calibrate a traitbased model for unicellular planktonic organisms characterized by four traits: cell size and investments in phototrophy, nutrient uptake, and phagotrophy. We use the model to predict how optimal trophic strategies depend on cell size under various environmental conditions, including seasonal succession. We identify two mixotrophic strategies: 'generalist mixotrophs' investing in all three investment-traits, and 'obligate mixotrophs' investing only in phototrophy and phagotrophy. We formulate two conjectures: 1) most cells are limited by organic carbon, however, small unicellulars are co-limited by organic carbon and nutrients, and only large photoautotrophs and smaller mixotrophs are nutrient limited; 2) trophic strategy is bottom-up selected by the environment, while optimal size is top-down selected by predation. The focus on cell size and trophic strategies facilitates general insights into the strategies of a broad class of organisms in the size range from micro-meters to millimeters which dominate the primary and secondary production of the world's oceans.
\end{abstract}




\section{Introduction}

Living organisms rely on uptake of carbon for structure and metabolism, and on nutrients to build the machinery supporting life. The means to acquire these resources defines an organism's trophic strategy (Andersen et al. 2015). Among terrestrial organisms, the trophic strategy can largely be divided between photoautotrophs (plants) and heterotrophs (animals), but in aquatic ecosystems many unicellular organisms employ a mixotrophic strategy that combines hetero- and phototrophy (Raven 1997; Stoecker 1998; Barton et al. 2013; Flynn et al. 2013). Flagellates and ciliates are prime examples of mixotrophs and the strategy can be found almost everywhere in the illuminated water column, in fresh water and in marine environments (Hartmann et al. 2012). Despite that marine unicellular communities fix about 50\% of global carbon (Westberry et al. 2008; Zhao and Running 2010), the role of the omnipresent mixotrophy is only beginning to be uncovered (Ward and Follows 2016). Because unicellular plankton engage in phagotrophy (engulfing food cells or particles) and phototrophy to varying degrees (Stoecker 1998), their trophic strategy is best described as a continuum spanning the range from pure photoautotrophs to pure heterotrophs (Jones 2000; Flynn et al. 2013; Våge et al. 2013). The optimal trophic strategy clearly depends on the environmental conditions: low concentrations of dissolved inorganic nutrients and high food concentrations must favor a mixotrophic strategy, while high concentrations of dissolved nutrients favor a photoautotrophic strategy.

Among photoautotrophs, the trophic strategy can be further diversified by different investments into phototrophy on one hand and inorganic nutrient uptake on the other (Shuter 1979; Raven 1984). Again, the environment is an important selector: low light and high nutrient concentrations, typical of conditions deep in the water column, will select for high investments in phototrophy, while high light and low nutrient concentrations, typical of summer surface conditions, will select for low investments in phototrophy but high investments in nutrient uptake (Bruggeman 2009; Berge et al. 2016). Taken together with the mixotrophic continuum, an organism's trophic strategy can be described as a point in the space spanned by the investments into phototrophy, nutrient uptake and phagotrophy (Flynn et al. 2013; Andersen et al. 2015), and the most successful strategy will depend on the environmental conditions.

Another important determinant of the trophic strategy is body size: photoautotrophs are small unicellular organisms, while all larger multicellular organisms are heterotrophs. The size-trophic strategy pattern contrast with terrestrial communities where body size of plants and animals overlaps considerably. Nevertheless, the size range of unicellular plankton spans eight orders of magnitude (Finkel et al. 2010) rougly the same size range as that between a bee and an elephant. Photoautotrophs acquire carbon through photosynthesis and, in aquatic systems, obtain essential nutrients through diffusive uptake of dissolved inorganic nutrients. Both processes are limited by cell size: for large cells, photosynthesis is limited by self-shading of photons (Morel and Bricaud 1981), and the diffusive nutrient uptake rate is limited by the number of uptake sites on the surface of the cell and the diffusion-limited nutrient flux towards the cell (Munk and Riley 1952). These effects result in a declining massspecific growth rate for photoautotrophs with size, making photoautotrophy viable only for small unicellular organisms. Cell size further regulates many other key organismal characteristics and biotic interactions, including clearance rates of 
phagotrophy (Hansen et al. 1997), preferred predator-prey size ratio (Hansen et al. 1994), metabolic rates (Litchman et al. 2007), sinking rate (Bienfang 1984), and mortality rate (Hirst and Kiørboe 2002). Cell size is therefore often viewed as the "master trait" to describe organisms (Litchman and Klausmeier 2008; Andersen et al. 2016) and the organization of communities (Elton 1926).

The importance of cell size makes it obvious to structure plankton community models by size (Banas 2011; Ward et al. 2012). However, such size-based models typically only consider two functional groups: phytoplankton and zooplankton, and they can therefore not resolve the entire trophic continuum. We disregard this classic distinction between phytoplankton and zooplankton and design a model where the trophic strategy of a unicellular organism with a given size is an emergent property. Our aim is to understand how the trophic strategy of unicellular planktonic organisms is determined by the interplay between cell size and environmental conditions. Or, in other words, how should a unicellular organism of a given size in a given environment make an optimal allocation between the various machineries involved in resource uptake (nutrients, light and food)?

By explicitly considering the interplay between optimal investments and cell size we combine previous models of mixotrophy (Bruggeman 2009; Berge et al. 2016) with purely size-based models (Ward and Follows 2016). This theoretical fusion of mixotrophy with size shows how organisms can break free of size-based constraints via changes in key investments to acquire nutrients and carbon, as conceptualized in Andersen et al. (2015). Because the model is based on fundamental trade-offs, it equally well describes the seasonal succession of different plankton species and the continuous acclimation of an ideal mixotrophic species to various conditions.

We use the model to gain broad insights into unicellular organisms in the size range from micro-meter to millimeter, which dominate the primary and secondary production in the ocean. We show that mixotrophy is better percieved as a strategy to gain carbon (and sometimes both nutrient and carbon) than to gain only nutrients, and how bottom-up effects are responsible for selecting trophic strategies while top-down effects selects for optimal sizes. Due to the model's conceptual simplicity, some organisms (like tiny heterotrophic bacteria, nitrogen-fixing diazotrophs, or large diatoms) fall outside its size- and nutrient-based scope. We discuss the trophic strategies employed by these organisms and how they fit into a size-based description.

\section{Model description}

The model represents a unicellular organism that acquires 1) organic carbon through photosynthesis, 2) dissolved inorganic nitrogen through diffusion, and 3) organic carbon and nitrogen through phagotrophy. The uptake and processing of carbon and nutrients are determined by four traits: cell size and investments in three resourceharvesting traits. The model structure largely follows the models developed in Berge et al. (2016) and Bruggeman (2009). However, it extends beyond these in two important ways. First, it incorporates the influence of cell size, which facilitates an understanding of how trophic strategy changes with size. Second, it enables a pure heterotrophic strategy that uses carbon from phagotrophy for metabolism and consequently leak excess nutrients. That addition reveals the existence of two distinctly different mixotrophic strategies. 
The functional responses are determined by investments $(\phi)$ in organelles and enzymes associated with each uptake pathway: investment in phototrophy $\phi_{L}$ (including pigments and enzymes for carbon fixation), investment in phagotrophy $\phi_{F}$ (including the membrane material for food vacuole formation and digestive enzymes) and investment in uptake of inorganic nitrogen $\phi_{N}$ (including enzymes for reduction of nitrate to ammonium and transmembrane porters). The investments are measured relative to the mass used for structure not associate with investments, $V(\mu \mathrm{gC})$, and consequently the total carbon mass of the cell becomes

$$
V_{\mathrm{tot}}=V\left(1+\phi_{L}+\phi_{N}+\phi_{F}\right)
$$

Investments confer a benefit in terms of higher affinity towards uptake of the resources (light/carbon, dissolved nutrients, or food) and a higher maximum uptake rate. The investments incur costs in terms of increased respiration and construction costs.

We consider nitrogen and carbon as the only essential elements and nitrate as the sole source of inorganic nitrogen. Inside the cell, fluxes of nitrogen and carbon, denoted by $J_{i}$ (mass flow $i$ being light $(L)$, nutrients $(N)$ or food $(F)$ ), are used to synthesize new biomass at a rate $J_{\text {tot }}$, which is constrained by the stoichiometric balance between carbon and nitrogen and respiratory costs to basal respiration $J_{R}$ and uptakes $R_{i} J_{i}$ (fig. 1).

\section{Affinities and maximum uptake rates}

The uptake of resource $X_{i}$ is governed by a standard saturating Holling type II functional response:

$$
J_{i}=M_{i} \frac{A_{i} X_{i}}{A_{i} X_{i}+M_{i}},(2)
$$

where $M_{i}$ is the maximum uptake rate $\left(\mu \mathrm{gC}\right.$ day $^{-1}$ or $\left.\mu \mathrm{gN}_{\text {day }}{ }^{-1}\right)$ and $A_{i}$ the affinity for uptake. These two parameters are determined as functions of the investment traits and cell size.

The affinity for uptake of each resource $A_{i}$ is:

$$
A_{i}=c_{i} V^{\theta_{i}} \frac{a_{i} \phi_{i} V}{a_{i} \phi_{i} V+c_{i} V^{\theta_{i}}}
$$

Here, $a_{i}$ is the amount of affinity gained per unit investment $\phi_{i}$. The investment can at most lead to an affinity $c_{i} V^{\theta_{i}}$, where $c_{i}$ and $\theta_{i}$ are parameters that determine how the maximum affinity scales with size. According to this formalism, investments have diminishing returns: at low investments $\left(a_{i} \phi_{i} V \ll c_{i} V^{\theta_{i}}\right)$ affinities increase linearly with investments, while affinities saturate at large investments to $c_{i} V^{\theta_{i}}$ (fig. 2A). Similarly, the scaling with size changes from linear for small cells to $\propto V^{\theta_{i}}$ for large cells (fig. 2B). Although the basic description of how affinities depend on investments remains the same for all kinds of resources, the exponent $\theta$ differs between uptakes:

Affinity for photosynthesis: Although photosynthesis can occur throughout the cell, larger cells are limited by self-shading of photons (the "package effect") and 
photosynthesis occurs predominantly at the surface of the cell (Morel and Bricaud 1981). For this reason, we consider that the affinity of photosynthetic efficiency scales with surface area, $A_{L} \propto V^{2 / 3}$ for larger cells. Therefore, the exponent regulating affinity to light is $\theta_{L}=2 / 3$ and the affinity can be written from equation (3) in terms of investment $\left(\phi_{L}\right)$ and size $(V)$ as:

$$
A_{L}=c_{L} V^{2 / 3} \frac{a_{L} \phi_{L} V}{a_{L} \phi_{L} V+c_{L} V^{2 / 3}} .
$$

If growth is only limited by light, the growth rate is roughly proportional to affinity divided by size, i.e. the specific affinity. For large investments the fraction approaches 1 , and affinities will be $\propto V^{2 / 3}$, and size-specific investments $\propto V^{-1 / 3}$, i.e. declining with size. Smaller cells will therefore have a higher size-specific photosynthetic affinity than larger cells and therefore a larger growth rate.

Affinity for nutrient uptake: The uptake of inorganic nutrients happens through diffusion to the cell. The uptake rate is limited by the number of uptake sites on the surface of the cell. However, the uptake removes nutrients near the cell surface and thereby creates a boundary layer of low nutrient concentration close to the cell surface compared to far from the cell (Munk and Riley 1952). Thus, the affinity for nutrients becomes limited by the speed of diffusion towards the cell surface rather than the surface of the cell, leading to an exponent $\theta_{N}=1 / 3$. Fiksen et al. (2013) reviewed the nutrient uptake in microbes and presented a modified form of the affinity for nutrient, which can be written in the same form as equation (3) (after some rearrangement as given in Appendix A) in terms of investment $\left(\phi_{N}\right)$ and size $(V)$ as:

$$
A_{N}=c_{N} V^{1 / 3} \frac{a_{N} \phi_{N} V}{a_{N} \phi_{N} V+c_{N} V^{1 / 3}}
$$

As with photosynthesis, small cells have a higher size-specific nutrient affinity than larger cells.

Affinity for prey: Affinity towards prey is determined by the clearance rate. Empirical data shows that the clearance rate scales linearly with cell volume, and thus $\theta_{F}=1$ (Kiørboe 2011), leading to an affinity for phagotrophy in terms of investment $\left(\phi_{F}\right)$ and size $(V)$ as:

$$
A_{F}=c_{F} V \frac{a_{F} \phi_{F}}{a_{F} \phi_{F}+c_{F}}
$$

Specific affinity $A_{F} / V$ is therefore independent of cell size.

Besides leading to a higher affinity, investments also result in a higher maximum uptake rate. Maximum uptake rates are not, as the affinities, limited by physical constraints and does therefore not saturate at high investments. Maximum uptake rates are therefore proportional to investments, in accordance with data showing that maximum uptake rates increase almost linearly with the cell volume $V$ (Aksnes and Egge 1991; Hansen et al. 1997; Marañón et al. 2007; Litchman 2012; Dao 2013):

$$
M_{i}=m_{i} \phi_{i} V,(7)
$$


where $m_{i}$ is the maximum uptake rate per unit investment $\phi_{i}$. Inserting the affinities (eq. [4], [5] and [6]) and the maximum uptake rates (eq. [7]) into equation (2) specifies the functional responses as a function of the traits.

\section{Investment and respiration costs}

The benefits of the investments $\phi_{i}$-- higher affinity and maximum uptake rates -come with costs in terms of building the structures, maintenance of the structures, and the uptake of resources. Costs of building the structures is represented by their biomass: $\sum_{i} \phi_{i} V$. Respiratory cost related to maintenance of structure are considered proportional to the investment, $\phi_{i} V$ :

$$
J_{R}=V\left(r_{0}+r_{L} \phi_{L}+r_{N} \phi_{N}+r_{F} \phi_{F}\right)
$$

where $r_{0}$ is the maintenance cost per unit mass of cell structure, and $r_{L}, r_{N}$ and $r_{F}$ are the maintenance costs per unit mass of light, nutrient and food harvesting apparatus, respectively. Note that $r_{L}$ is assumed larger than $r_{N}$ and $r_{F}$ as the photosynthetic apparatus often occupy a large fraction of the cell mass (see Appendix $\mathrm{C}$ for discussion of parameter values). Additionally there are metabolic costs associated with the actual uptake of resources due to enzymatic activities and mobilization for synthesis. These uptake costs are proportional to the uptakes $J_{i}: R_{L} J_{L}, R_{N} J_{N}$ and $R_{F} J_{F}$ for photosynthesis, uptake of nutrients and uptake of food, respectively, where $R_{i}$ 's are costs per unit of resource uptake. The total metabolic cost for cell of size $V$ is $J_{R}+\sum R_{i} J_{i}$.

\section{Trade-off among investments}

Besides the structural and maintenance costs related to investments in different uptake strategies, there is also a trade-off among different investments. Because of the limitation of space within a cell, we limit the total investment to being less than the mass of structure, i.e. $\sum \phi_{i} \leqslant 1$. Knowing that investments in phototrophy rarely exceed $50 \%$ of total cell mass, and that investments in phagotrophy are small (around 10\%) (Raven 1997), this seems like a reasonable limit. In this way an increased investment in one resource uptake will decrease investments in others.

\section{Down-regulation of nutrient uptake}

The uptake of dissolved nutrients needs to be treated specially because the cell may have insufficient carbon for the metabolic costs of uptake and assimilation, particularly under conditions of low light. In that case, we assume that the cell downregulates the uptake of nutrients by a factor $\rho$ between 0 and 1 , such that there will be no excretion of nutrients while synthesizing new structure. This assumption leads to the factor (See appendix B for derivation):

$$
\rho=\frac{J_{L}-J_{R}-R_{L} J_{L}-R_{F} J_{F}}{\left(R_{N}+Q_{C N}\right) J_{N}}
$$

with $Q_{C N}$ being the C:N mass ratio. The actual nutrient uptake will be the potential nutrient uptake multiplied by this factor: $\rho J_{N}$. Since the actual nutrient uptake cannot exceed the potential uptake $\left(J_{N}\right)$, and also cannot be negative, (9) is limited to lie in the range $0 \leq \rho \leq 1$ (eq. [B3] in Appendix B). 


\section{Synthesis of biomass}

The assimilated carbon, nutrients and food are combined to synthesize new structure and investments. Different investments could have different $\mathrm{C}: \mathrm{N}$ ratios, but this sophistication is omitted here for simplicity and we assume that the resource harvesting machineries, the structural components of the cell, and assimilated food all have the same C:N mass ratio, $Q_{C N}$ (units of $\mu \mathrm{gC} \mu \mathrm{gN}^{-1}$ ). The total available carbon is then $J_{L}+J_{F}-J_{R}-R_{L} J_{L}-R_{N} \rho J_{N}-R_{F} J_{F}$ where $J_{L}+J_{F}$ represents the total uptake of carbon from light and phagotrophy, and $J_{R}$ and $R_{L} J_{L}+R_{N} \rho J_{N}+R_{F} J_{F}$ represent the costs of maintenance and uptake, respectively. The flux of nutrient involves the nutrients locked up in consumed food, $J_{F} / Q_{C N}$ (assuming equal stoichiometry of food and consumer), and nutrients taken up directly out of the dissolved nutrient pool, $\rho J_{N}$. That is, the flux of nutrient is: $J_{F} / Q_{C N}+\rho J_{N}$. The carbon required to synthesize the nutrients to biomass is $J_{F}+Q_{C N} \rho J_{N}$, again with same stoichiometric conversion. The combination of total carbon and nutrient fluxes is performed following Liebig's law of the minimum:

$$
J_{\text {tot }}=\min \left[J_{L}+J_{F}-J_{R}-R_{L} J_{L}-R_{N} \rho J_{N}-R_{F} J_{F}, J_{F}+Q_{C N} \rho J_{N}\right]
$$

$J_{\text {tot }}$ is the total flux of carbon (and nutrients) available for synthesis. Note that the synthesis is not limited by a maximum synthesis capacity; limitation of synthesis is taken care of by the limitation of uptake of light, nutrients and food in the functional responses (eq. [2]). The mass specific synthesis rate (units per time) is the total flux of carbon divided by the mass of the cell (eq. [1]):

$$
\mu=\frac{J_{\text {tot }}}{V\left(1+\phi_{L}+\phi_{N}+\phi_{F}\right)}
$$

Since we assume that the size of a specific organism remains fixed throughout its lifetime, biomass synthesis results in an increase in population growth rate. Therefore, subtracting predation mortality gives the final growth rate of a population with cell size $V$ and traits $\phi_{i}\left(\right.$ day $\left.^{-1}\right)$ as:

$$
g=\mu-\delta V^{-1 / 4}
$$

where $\delta$ is a mortality constant. Here we assume that the mortality rate declines with cell size with exponent $-1 / 4$. This scaling reflects average mortality from larger predators (Hirst and Kiørboe 2002; Andersen and Beyer 2006). Specifically, it assumes that smaller organisms are more vulnerable to predation than larger ones. Of course, in nature mortality may vary with size more complexly (see discussion topic 'Environment selects for trophic strategy; predators select for size').

\section{Model parameterization}

The trait-based formulation of the model means that the parameters in functional responses (affinity $A_{i}$ and maximum uptake rate $M_{i}$ ) are determined by the investments in resource harvesting traits $\left(\phi_{L}, \phi_{N}, \phi_{F}\right)$ and cell size $(V)$ through the trade-off parameters $a_{i}$ (affinity gained per investment of resource), $c_{i}$ (maximum affinity scales with size) and $m_{i}$ (maximum uptake rate per investment). The traits likewise determine basal metabolism through the parameters $R_{i}$ (costs per unit of resource uptake) and $r_{i}$ (maintenance costs per unit mass). We determine these 
parameters such that affinities, maximum uptake rates and respiration of typical plankton cells conform with observations (Taguchi 1976; Moloney and Field 1989; Hansen et al. 1997; Kiørboe 2011; Edwards et al. 2012; Ward et al. 2012; Marañón et al. 2013). We assume that on average, trait values for investments in the photosynthetic machinery $\left(\phi_{L}\right)$, nutrient harvesting $\left(\phi_{N}\right)$, and phagotrophy $\left(\phi_{F}\right)$ are $0.5,0.2$, and 0.2 , respectively, as a reasonable set of investments for mixotrophs where the dominant investment is in phototrophy (Raven 1997). To account for variations between cells due to the taxonomic differences and the adaptive capability (Shuter 1979; Raven 1984; Smith et al. 2011), we varied these traits around the prescribed values. The calibration procedure and the match between data and model outcomes are described in appendix C, and parameter values in Table 1.

\section{Results}

\section{Gains, losses and growth rates}

We first examine a mixotroph with fixed investment in resource harvesting traits $\left(\phi_{L}=0.5, \phi_{N}=0.2, \phi_{F}=0.2\right)$ living under environmental conditions corresponding to early spring conditions (medium light intensity $X_{L}=33 \mathrm{~W} \mathrm{~m}^{-2}$, high nutrient concentration $X_{N}=66 \mu \mathrm{gN}$ liter $^{-1}$, and low food concentration $X_{F}=17 \mu \mathrm{gC}$ liter $^{-1}$ ) to illustrate the internal flows of carbon and nutrients in the cell (fig. 3). Note that the food concentration is equally available to all cell sizes, which implies a flat food size spectrum (Andersen and Beyer 2006). The food concentration is significantly lower than typical values of total particulate organic carbon (20-700 $\mu \mathrm{gC} \mathrm{liter}^{-1}$ ) (Stramska 2009), representing the fact that only a fraction is available to any given predator due to preferred prey:predator size ratios. Although each resource is equally available to all cells, uptake of resources will differ because of size constraints on affinities and maximum uptake rates.

Under these conditions, large cells $(V>5.6 \mu \mathrm{gC}$; right dotted vertical line in fig. 3A) obtain most of their nutrients and carbon from phagotrophy (magenta line is higher than green line). Therefore, these large cells are predominantly heterotrophic.

According to our assumption of fixed C:N mass ratio, $Q_{C N}$, of the food particles, respiration of acquired carbon leads to an excess of nutrients during synthesis, which are leaked. Medium-sized cells $(0.17 \mu \mathrm{gC}<V<5.6 \mu \mathrm{gC}$; size range bounded by the left and right dotted vertical lines in fig. 3A) obtain more carbon from photosynthesis than from phagotrophy (green line is higher than the magenta line in fig. 3A), but the gain of nutrients from phagotrophy is higher than the gain from diffusive nutrient uptake (magenta line higher than the blue lines). Conversely, smaller cells $(V<0.17$ $\mu \mathrm{gC}$; left dotted vertical line in fig. 3A) have a higher gain from diffusive uptake of nutrients than from phagotrophy and they are therefore predominantly photoautotrophs. Further, these small cells obtain insufficient carbon to take up all nitrogen available to them. Consequently they down-regulate uptake of nutrients ( $\rho<1$; thick blue line is lower than thin blue line). As a result, small cells are carbon (light) limited.

The population growth rate of cells ( $g$ in eq. [12]; fig. 3C) as a function of size is obtained by subtracting size-specific total losses (respiration and mortality) (fig. 3B) from the size-specific gains (fig. 3A). At very small sizes $\left(V<2.2 \times 10^{-7} \mu \mathrm{gC}\right.$ ), losses due to mortality are higher than the gains from photosynthesis and nutrient uptake, and thus the population growth rate is negative. For larger cell sizes, size 
specific losses due to mortality decreases, which make population growth rates positive. However, again for very large cells $\left(V>7 \times 10^{3} \mu \mathrm{gC}\right)$, the total gain from phagotrophy is insufficient to compensate the losses (specifically due to respiration) and thus the growth rate once again becomes negative in this size range. Note the large size range - approx. $6 \times 10^{-6} \mu \mathrm{gC}$ to $10^{-2} \mu \mathrm{gC}$ - where population growth rate changes relatively less than outside that range (varies within 0.2 and 0.26 day $^{-1}$ ). These predictions of how different uptakes provide benefit and change growth rates will influence how cells invest in different resource harvesting traits, e.g., very small cells are expected to invest relatively more in phototrophy than nutrient uptake, while very large cells are expected to invest solely in phagotrophy.

\section{Optimal strategies with size}

Investments in resource harvesting traits determine a cell's trophic strategy. The optimal investments $\phi_{i}^{*}$ (here the '*' symbol represents optimal) are the investments that maximize population growth rate (fig. 4). Photoautotrophy, i.e. investments primarily in phototrophy $\left(\phi_{L}\right)$ and nutrient uptake $\left(\phi_{N}\right)$, is the optimal trophic strategy for smaller cells (fig. 4A). In contrast to the cells with fixed investments in fig. 3, the optimal cells will not down-regulate their nutrient uptake. Instead they adjust their investments in nutrient uptake and phototrophy to balance both uptakes such that $\rho=1$. Small optimal cells are therefore co-limited by carbon and nutrients, and not, as the cells with fixed investment, carbon limited. As size increases, investments in phagotrophy $\left(\phi_{F}\right)$ increases, marking a transition from a photoautotrophic strategy to a mixotrophic strategy, here arbitrarily defined at the point where relative investments in phagotrophy compared to investments in phototrophy exceeds $3 \%\left(\phi_{F}^{*} /\left(\phi_{L}^{*}+\right.\right.$ $\left.\phi_{F}^{*}\right)>0.03$; left-most dotted vertical line in fig. $\left.4 \mathrm{~A}\right)$. These mixotrophs invest in all three resource harvesting traits and consequently we term them "generalist mixotrophs". At a certain size (approx. $2 \mu \mathrm{gC}$; middle dotted vertical line in fig. 4A), phagotrophy provides all the required nutrients, and cells significantly reduce their investments in nutrient harvesting (fig. 4B). Beyond this size, cells excrete excess nutrients, and since phagotrophy provides the sole supply of nutrients for growth, we call these cells "obligate mixotrophs". Very large cells completely stop investing in photosynthesis and nutrient uptake and a purely phagotrophic (heterotrophic) strategy is optimal (here defined as when relative investments in phototrophy compared to investments in phagotrophy is below $3 \%\left(\phi_{L}^{*} /\left(\phi_{L}^{*}+\phi_{F}^{*}\right)<0.03\right.$; right-most dotted vertical line in fig. $4 \mathrm{~A})$ ). Note the wide range of combinations of trait values (shaded colors in fig. 4A) that indicates growth rates very close to the optimal one.

\section{Influence of resource concentrations}

The optimal trophic strategy at a particular size is determined by the resource concentrations (fig. 5). To illustrate the influence of changing environmental conditions, we calculate the optimal strategies under resource concentrations ranging from oligotrophic to eutrophic conditions by changing light and nutrient conditions (fig. 5B), for fixed food concentration $\left(X_{F}=17 \mu \mathrm{gC}\right.$ liter $\left.^{-1}\right)$. Oligotrophic situations (high light and low nutrients) reflect a tropical system or surface summer conditions in a temperate system, while eutrophic situations (abundant nutrients and low light) correspond to spring conditions in a temperate system. As before, a smooth transition from photoautotrophy to heterotrophy through mixotrophy is observed as cell size increases (fig. 5C). Under oligotrophic conditions, obligate mixotrophs, investing 
only in phototrophy and phagotrophy, dominate over a broad size range. Large photoautotrophs can be observed under very high light conditions combined with high nutrient and low food concentrations (fig. 5E), situations similar to the early spring in a temperate system. On the other hand, heterotrophs may be smaller, and mixotrophs become increasingly heterotrophic (fig. 5G) as food concentration increases. The predicted size ranges of photoautotrophs, mixotrophs and heterotrophs correspond fairly well with observed size ranges (fig. 5A vs. 5C) (Andersen et al. 2016). The model misses, however, the small heterotrophs and overestimates the size of mixotrophs.

\section{Seasonal succession}

Varying light intensity, nutrient concentration and prey abundance throughout a season creates a seasonal succession of optimal trophic strategies (fig. 6A). The temporal variation of the resource concentrations was inspired by observations of light (Acevedo-Trejos et al. 2014), nitrate (Zervoudaki et al. 2009) and prey (Irigoien 2005). During winter, when the nutrient concentration is high and light intensity and food abundance are low the environmental conditions favor small photoautotrophs (fig. 6B, C). Larger cells are heavily affected by self-shading under low light condition and thus cannot perform better than the small ones. As the season progresses, the increasing light intensity together with sufficient nutrient provides benefits to relatively larger photoautotrophs. Moreover, due to the increase in food availability, heterotrophs also achieve high growth rates during this period. During summer conditions, when nutrients are exhausted, food concentration is moderate and light levels are high, relatively small obligate mixotrophs dominate. In this way, the successional pattern of trophic strategies changes from autotrophs to heterotrophs to mixotrophs, and eventually back to small photoautotrophs. As seen earlier, a large size range of cells has growth rates similar to the optimal ones (the contour lines in fig. $6 \mathrm{~B}$ are almost vertical where they cross the thick line).

\section{Discussion}

We have described the trophic strategy of unicellular plankton as a resource allocation problem between three resources. Such problems are often cast in economic terms as an optimization of growth, e.g., by allocation between chlorophyll and nutrient uptake in phytoplankton (Shuter 1979; Raven 1984; Geider et al. 2009) or plants (allocation between leaves and roots; Poorter et al. 2011; Zhang et al. 2015). Other examples are allocation between phototrophy and uptake of dissolved organic carbon (Troost et al. 2005; Ward et al. 2011) and allocation between defense and growth (Caldwell et al. 1981; Wang et al. 2015). An extra dimension is added imposing the physical constraints determined by cell size. Cell size changes the optimal allocation in a manner similar to how optimal allocation changes in plants during ontogeny (Lohier et al. 2014). However, for a unicellular organism with limited ontogenetic growth, the optimal allocation becomes a life history choice of trophic strategy. The systematic changes in optimal strategy with cell size highlights the importance of body size for structuring macro-ecological patterns among microbial primary and secondary producers in aquatic environments (Huete-Ortega et al. 2014).

\section{The size structure of trophic strategies}


The model reproduces the well-known relationship between the size of aquatic organisms and their trophic strategies (Kiørboe et al. 1990; Kiørboe 1993; Andersen et al. 2016): small cells are predominantly photoautotrophic, whereas a heterotrophic mode of nutrition dominates with increasing size. This relationship emerges because of the differences in scaling with cell size of investment returns from phototrophy, nutrient uptake and phagotrophy. If investments are independent of size, mass specific affinities scale as $V^{-1 / 3}, V^{-2 / 3}$ and $V^{0}$ for light, nutrients and prey uptake, respectively. Small cells thus get high mass specific $\mathrm{C}$ and $\mathrm{N}$ from photosynthesis and diffusive nutrient uptake favoring photoautotrophy, whereas larger cells suffer increasingly from self-shading and diffusion limitation favoring phagotrophy. Accordingly, the model predicts how small cells invest mainly in phototrophy and nutrient uptake, whereas large cells invest predominantly in phagotrophy. While the observed changes in trophic strategy with size follow directly from size scaling of affinities (Andersen et al. 2015; Andersen et al. 2016), and are independent of the trait-based model per se, the model illustrates how cells use investments to counteract the physical constraints set by cell size and adjust uptake of limiting nutrient to achieve co-limitation.

\section{Two types of mixotrophy}

While pure photoautotrophs and heterotrophs can be considered trophic specialists, the dominant optimal modelled strategy is a trophic generalist, a mixotroph. Among the mixotrophs, a pattern of two distinct types emerges: generalist mixotrophs invest in all three resource harvesting traits (photosynthesis, nutrient uptake and phagotrophy) whereas obligate mixotrophs invest only in photosynthesis and phagotrophy. Our generalist mixotroph corresponds to the type I \& II mixotroph in the classification of Stoecker (1998) ("ideal" mixotrophs and phagocytic algae) and our obligate heterotrophs to "type III" mixotrophs. In terms of nutrient and carbon uptake strategies, mixotrophs represent cells facing limitation of either nutrients or carbon: generalist mixotrophs can be considered primarily photoautotrophic cells that engage in phagotrophy to supplement the limited diffusive flux of dissolved nutrients. Obligate mixotrophs can be considered primarily heterotrophs that avoid metabolizing carbon from phagotrophy (which entail excreting excess nutrients) by fuelling metabolism with carbon from phototrophy. In terms of cell size, generalist mixotrophs are smaller than obligate mixotrophs. Both types will be favored in high light environments, with the generalists particularly prevalent under oligotrophic conditions.

\section{Environment selects for trophic strategy; predators select for size}

The shape of the optimal growth rate as a function of trophic strategy and cell size reveals the selective forces acting on the plankton community. Two aspects are noteworthy: 1) a wide range of trophic strategies have fairly similar growth rates (shaded areas in Fig. 4A). This implies that competitive exclusion between species with different strategies will be slow and consequently that many sizes and strategies can coexist in a variable environment (Acevedo-Trejos et al. 2014), which help to explain the large species diversity observed in planktonic communities (Hutchinson 1961). 2) A wide range of sizes have growth rates close to the optimum. This implies that the resource environment does not select for a dominant size of organisms, challenging the notion that cell size is selected by the scaling of diffusion limitation with cell size (Kiørboe 1993). Rather, in an oligotrophic situation, cells are able to 
partly compensate for lower nutrient encounter rates by investments in nutrient harvesting and phagotrophy. Instead, the population growth rate as a function of size is strongly shaped by the predation mortality; as an example we showed how the level of predation was important in determining the lower viable size of plankton (fig. 3).

The selection of optimal cell sizes depends on how predation mortality varies with size. We used a predation mortality that is smoothly decreasing with size with a "metabolic" scaling ( $-1 / 4$ exponent), to represent the average predation mortality with size in plankton (Kiørboe and Hirst 2014). However, the predation pressure at any time in a water column is unlikely to follow such a smooth function; rather it is shaped by the exact size composition of predators present at any given time and place. Predatory copepods are size-selective for prey, preferring prey typically a factor 1001000 smaller than themselves (Hansen et al. 1997). The dominant size group of predators in the succession will therefore impose a strong predation pressure on a particular size of unicellular plankton, and thereby select against this size range. While predation is clearly selecting for the size of prey, predators can be expected to be less selective on the trophic strategy of their prey (Gianuca et al. 2016). Selection for optimal trophic strategy, therefore, is mainly done by the resource environment. These two insights (predation selects for size while the resource environment selects for trophic strategy) can be distilled into a general conjecture about the relative importance of bottom up processes (selection by the environment) versus top-down processes (selection by predation) in the seasonal plankton succession (Evans and Parslow 1985; Behrenfeld and Boss 2014): bottom-up processes dominate the selection for trophic strategy, while top-down processes are more important for sizeselection.

\section{Model architecture and limitations}

The model successfully captures the broad patterns of trophic strategy for dominant organisms such as ciliates, flagellates and dinoflagellates. Other organisms have managed to break free of the limitations imposed by the general size-scaling rules, at least to some degree. Important examples are diatoms, filamentous phytoplankton, heterotrophic nanoflagellates and bacteria:

Diatoms are purely photoautotrophic and are typically larger than the largest photoautotrophs predicted here. They achieve this feat by producing a silicate frustule that contains a vacuole (Sicko-Goad et al. 1984; Thingstad et al. 2005) whereby they increase their surface area without changing their biomass. In terms of our model this implies an increase in the values of the trade-off coefficients associated with light and nutrient harvesting, $a_{L}$ and $a_{N}$. The costs of this obvious benefit is a reliance on silicate and that the shell inhibits them from engaging in phagotrophy, forcing them to be trophic specialists.

Filamentous (chain-forming) phytoplankton are also often larger than the largest photoautotrophs of our model. Chain formation is perceived as a mechanism to escape microzooplankton grazing (Hessen and van Donk 1993; Long et al. 2007; Bjærke et al. 2015), but the larger size compromises nutrient uptake and light harvesting. The filamentous morphology ensures, however, that these disadvantages are minimized by changing the aspect ratio. Still, these types of plankton are expected to occur under conditions of high nutrient concentrations and high light. 
Heterotrophic nanoflagellates are small heterotrophs feeding mainly on bacteria, however, primarily by diffusional encounters, not by direct interception (Fenchel 1984; Shimeta 1993). Since our model does not account for diffusional encounters, it is unable to capture heterotrophic nanoflagellates.

Finally, bacteria also engage in diffusional uptake of dissolved organic matter (osmoheterotrophy) and some cyanobacteria can grow without external sources of fixed nitrogen due to their capability of fixing atmospheric nitrogen gas (diazotrophy). Neither strategy is accounted for. Diffusional uptake of organic matter could be added as a trait, with a similar trade-off structure and size-scaling as the uptake of nutrients. Just like diffusional uptake of nutrients, it would be a strategy that favours small organisms (Andersen et al. 2016) - the hetereotrophic bacteria. Many cyanobacteria, such as the abundant Prochlorococcus spp., fix nutrients via diazotrophy. The tradeoff involved with diazotrophy likely involved the need to maintain an oxygen-free environment within the cell. Phagotrophy allows oxygen to enter cells. As a result, diazotrophy constrains such organisms to purely phototrophic assimilation of carbon.

Even though all these organisms are not directly described by the model, their strategies are still shaped by their response to the physical limitations imposed by the trade-offs with cell size. Despite apparently breaking free of these limitations by evolutionary inventions, they can do so only to some extent. For example, even though diatoms are larger than the photoautotrophs predicted here, their upper size is eventually limited by self-shading and diffusion limitation.

\section{Implications}

Even if it cannot capture all strategies, this model faithfully represents the general limitations that all unicellular organisms face along a size gradient. Our model centers on trade-offs involved in specific strategies to acquire carbon and nutrient - i.e., it wrestles with the inherent, size-based costs and benefits of each strategy. It would be fascinating, in a future modeling effort, to explore how these strategies interact in a fully dynamical model. In that model, competition and predator-prey interactions could become represented explicitly. Furthermore, such a model could embrace feedbacks between food availability and optimal strategies, since they undoubtedly influence each other. Thus, such a future model would lead to richer and more complex results. Nonetheless, we anticipate that the general result here - optimal trophic strategies shift with body size - should emerge from these more complex and realistic scenarios. This will highlight the role of size-based trade-offs as the hidden keys to understand the rich variety of trophic strategies proliferating among unicellular plankton, from pure phototrophs to pure heterotrophs.

\section{Acknowledgments}

This work is part of the 'Centre for Ocean Life', a VKR center of excellence supported by the Villum foundation. SC was supported by the HC Ørsted COFUND postdoc fellowship. We wish to thank Prof. Spencer Hall and two anonymous referees for their suggestions and constructive comments. 


\section{Appendix A:}

\section{Nutrient uptake}

According to equation (7) of Fiksen et al. (2013), the nutrient uptake affinity $\left(A_{N}\right)$ of a cell can be written as

$A_{N}=\frac{4 \pi D r n s}{n s+\pi r(1-p)},(A 1)$

where $D\left(\mathrm{~cm}^{2}\right.$ day $\left.^{-1}\right)$ is the molecular diffusion coefficient, $r(\mathrm{~cm})$ is cell radius, $n$ is the number of uptake sites per cell, $s(\mathrm{~cm})$ is the uptake site radius, $p$ is the fraction of cell surface area covered by uptake sites $\left(p=\frac{n \pi s^{2}}{4 \pi r^{2}}\right)$ and $n$ the number of nutrient uptake sites. Assuming that the number of nutrient uptake sites $(n)$ is proportional to the cell volume and to the investment in nutrient uptake $\left(\phi_{N}\right)$, we can write it as $n=c \phi_{N} r^{3}$ with $c$ being a proportionality constant. Inserting that in (A1) we can write $A_{N}$ as:

$A_{N}=4 \pi D r \frac{4 \operatorname{cs} D \phi_{N} r^{3}}{4 \operatorname{cs} D \phi_{N} r^{3}+4 \pi D r}($ as $s \ll r)$

$=c_{N} V^{1 / 3} \frac{a_{N} \phi_{N} V}{a_{N} \phi_{N} V+c_{N} V^{1 / 3}},(A 2)$

using $r=C_{\text {const }} V^{1 / 3}$ where $C_{\text {const }}$ is the constant of conversion from mass to radius.

For the sake of simplicity we introduced two constant terms, $c_{N}$ (determines how the maximum nutrient affinity scales with size) and $a_{N}$ (determines the amount of affinity gained per unit investment $\phi_{N}$ ) where these constants can be expressed in terms of other constants as $c_{N}=4 \pi D C_{\text {const }}$ and $a_{N}=4 c s D C_{\text {const }}{ }^{3}$. We chose the following parameter values to calculate $A_{N}: \phi_{N}=0.2, D=8.64 \times 10^{-1} \mathrm{~cm}^{2}$ day $^{-1}$ (Fiksen et al. 2013), $s=1 \times 10^{-7} \mathrm{~cm}$ (Berg and Purcell 1977), $c=\frac{n}{\phi_{N} r^{3}}=\frac{4 p r^{2} s^{-2}}{\phi_{N} r^{3}}=5.144 \times$ $10^{14} \mathrm{~cm}^{-3}$ (using $p=1.286 \times 10^{-4}$ and $r=5 \times 10^{-4} \mathrm{~cm}$ from Fiksen et al. (2013)), $C_{\text {const }}=1.5 \times 10^{-2} \mathrm{~cm}\left(\mu \mathrm{gC}^{1 / 3}\right)^{-1}$ (Andersen et al. 2016). This gives $c_{N}=1.62 \times$ $10^{-4}$ liter day $\mu^{-1} \mathrm{gC}^{-1 / 3}, a_{N}=0.6$ liter day ${ }^{-1} \mu \mathrm{gC}^{-1}$ (using $\mathrm{cm}^{3}=10^{-3}$ liter).

\section{Appendix B:}

\section{Reduction in nutrient uptake}

We assume that the cell reduces its nutrient uptake by a factor $\rho$ under light limitation to restrict the excess nutrient uptake (that will ultimately be excreted from the cell) which appears costly at that situation. No excretion occurs when the flux of carbon $\left(J_{L}+J_{F}-J_{R}-R_{L} J_{L}-R_{N} \rho J_{N}-R_{F} J_{F}\right)$ and nutrient $\left(J_{F} / Q_{C N}+\rho J_{N}\right)$ available for synthesis has the correct ratio to synthesize new biomass. The criterion for the two fluxes being compatible to create structure with C:N of $Q_{C N}$ is then:

$$
J_{L}+J_{F}-J_{R}-R_{L} J_{L}-R_{N} \rho J_{N}-R_{F} J_{F}=J_{F}+Q_{C N} \rho J_{N} .
$$


Isolating $\rho$ gives:

$$
\rho=\frac{J_{L}-J_{R}-R_{L} J_{L}-R_{F} J_{F}}{\left(R_{N}+Q_{C N}\right) J_{N}}
$$

Since the actual nutrient uptake $\left(\rho J_{N}\right)$ cannot exceed the potential uptake $\left(J_{N}\right)$, and also cannot be negative, i.e. $0<\rho<1$ :

$$
\rho=\max \left[0, \min \left[1, \frac{J_{L}-J_{R}-R_{L} J_{L}-R_{F} J_{F}}{\left(R_{N}+Q_{C N}\right) J_{N}}\right]\right] .
$$

\section{Appendix C:}

\section{Calibration of parameters}

To find the parameters related to affinities, i.e. the amount of affinities gained per investment $\left(a_{i}\right)$ and the parameters $c_{\mathrm{i}}$ that determines how the maximum affinity scales with size, we use data for the affinities for light (fig. C1A) and food (fig. C1C). Parameters $a_{N}$ and $c_{\mathrm{N}}$ related to nutrient affinity (fig. C1B) are determined using the parameters given in Fiksen et al. (2013) (see appendix A). While calibrating parameters, it is assumed that the data points for a particular resource are collected under non-limiting conditions of other resources. These parameters can also show variations due to the taxonomic difference in spite of having same size (Barton et al. 2013). Thus we varied the parameters around the calibrated values in the simulated regions. The ranges around those values are presented in Table 1 and created the shaded regions in figs. C1A-C. The data show that the affinity for light is constrained by size (i.e. scales with $V^{2 / 3}$ ), while affinity for nutrient uptake changes from a linear scaling with size to the nutrient limited scaling with size $\left(\propto V^{1 / 3}\right)$ in the middle of the size range.

Similarly, the maximum uptake rates per investment $\left(m_{i}\right)$ are calibrated using data for maximum uptake rates for light (fig. C1D), nutrient (fig. C1E), and food (fig. C1F).

To find the parameters related to maintenance $\left(r_{i}\right)$, we assume $r_{0}=0.04 \mathrm{day}^{-1}$, $r_{L}=0.18$ day $^{-1}, r_{N}=0.06$ day $^{-1}, r_{F}=0.04$ day $^{-1}$. We assumed high metabolic cost of photosynthesis relative to phagotrophy following Raven's (1997) argument. He argued that the photosynthetic apparatus (including machinery of nutrient uptake) can occupy up to $50 \%$ of the cell biomass and consume $50 \%$ of the energy, whereas maintenance costs of the phagotrophic apparatus remain $<10 \%$. Metabolic costs of uptake, assimilation and synthesis $\left(R_{i}\right)$ through the three pathways (photosynthesis, nutrient uptake and phagotrophy) are assumed equal and calibrated from the data for respiration rate scales to be $0.08 \mu \mathrm{gC} / \mu \mathrm{gC}$ (fig. $\mathrm{C} 1 \mathrm{G}$ ).

The list of all parameter values and their units are provided in Table 1. To ensure that the model outcomes are independent of the data used to calibrate the model parameters, the actual photosynthetic rate $J_{L}$ (fig. $\left.\mathrm{C} 2 \mathrm{~A}\right)$, affinities $\left(A_{N}, A_{\mathrm{F}}\right)$ vs maximum uptake rates $\left(M_{N}, M_{F}\right)$ for nutrient (fig. C2B) and food uptake (fig. C2C) are plotted with observations different from the data used to calibrate the model. Notice that the slope of actual photosynthetic rate decreases at high size range of the organisms (fig. C2A). Moreover, the rate of increase in the affinity for nutrient uptake 
slows down for large organisms (as described in fig. 2) compared to maximum nutrient uptake rates which results in a bend in fig. C2B.

\section{Literature Cited}

Acevedo-Trejos, E., G. Brandt, and A. Merico. 2014. Mechanisms shaping phytoplankton community structure and diversity in the ocean. Scientific Reports 5 , 8918.

Aksnes, D. L., and J. K. Egge. 1991. A theoretical model for nutrient uptake in phytoplankton. Marine Ecology Progress Series 70:65-72.

Andersen, K. H., D. L. Aksnes, T. Berge, $\varnothing$. Fiksen, and A. Visser. 2015. Modelling emergent trophic strategies in plankton. Journal of Plankton Research 37:862-868.

Andersen, K. H., T. Berge, R. J. Goncalves, M. Hartvig, J. Heuschele, S. Hylander, N. S. Jacobsen, et al. 2016. Characteristic sizes of life in the oceans, from bacteria to whales. Annual Review of Marine Science 8:1-25.

Andersen, K. H., and J. E. Beyer. 2006. Asymptotic Size Determines Species Abundance in the Marine Size Spectrum. The American Naturalist 168:54-61.

Banas, N. S. 2011. Adding complex trophic interactions to a size-spectral plankton model: Emergent diversity patterns and limits on predictability. Ecological Modelling 222:2663-2675.

Barton, A. D., A. J. Pershing, E. Litchman, N. R. Record, K. F. Edwards, Z. V. Finkel, T. Kiørboe, et al. 2013. The biogeography of marine plankton traits. Ecology Letters 16:522-534.

Behrenfeld, M. J., and E. S. Boss. 2014. Resurrecting the Ecological Underpinnings of Ocean Plankton Blooms. Annual Review of Marine Science 6:167-194.

Berg, H. C., and E. M. Purcell. 1977. Physics of Chemoreception. Biophysical Journal 20:193-219.

Berge, T., S. Chakraborty, P. J. Hansen, and K. H. Andersen. 2016. Modelling succession of key resource harvesting traits of mixotrophic plankton populations. ISME Journal (published online) doi: 10.1038/ismej.2016.92.

Bienfang, P. K. 1984. Size structure and sedimentation of biogenic microparticulates in a subarctic ecosystem. Journal of Plankton Research 6:985-995.

Bjærke, O., P. R. Jonsson, A. Alam, and E. Selander. 2015. Is chain length in phytoplankton regulated to evade predation? Journal of Plankton Research 37:11101119.

Bruggeman, J. 2009. An adapting ecosystem manoeuvring between autotrophy and heterotrophy. In Succession in plankton communities - A trait-based perspective ( $p p$ 71-100). PhD Thesis. Department of Theoretical Biology. Vrije Universiteit, 
Amsterdam.

Caldwell, M. M., J. H. Richards, D. A. Johnson, R. S. Nowak, and R. S. Dzurec. 1981. Coping with herbivory: Photosynthetic capacity and resource allocation in two semiarid Agropyron bunchgrasses. Oecologia 50:14-24.

Dao, M. H. 2013. Reassessment of the cell surface area limitation to nutrient uptake in phytoplankton. Marine Ecology Progress Series 489:87-92.

Edwards, K. F., M. K. Thomas, C. A. Klausmeier, and E. Litchman. 2012. Allometric scaling and taxonomic variation in nutrient utilization traits and maximum growth rate of phytoplankton. Limnology and Oceanography 57:554-566.

Elton, C. S. 1926. Animal Ecology. University of Chicago Press, Chicago, IL.

Evans, G. T., and J. S. Parslow. 1985. A model of annual plankton cycles. Biological Oceanography 3:327-347.

Fenchel, T. 1984. Suspended Marine Bacteria as a Food Source. In M. Fasham, ed., Flows of Energy and Materials in Marine Ecosystems; NATO conference series (pp. 301-315). Plenum Press, New York.

Fiksen, $\varnothing .$, M. J. Follows, and D. L. Aksnes. 2013. Trait-based models of nutrient uptake in microbes extend the Michaelis-Menten framework. Limnology and Oceanography 58:193-202.

Finkel, Z. V., J. Beardall, K. J. Flynn, A. Quigg, T. A. V Rees, and J. A. Raven. 2010. Phytoplankton in a changing world: Cell size and elemental stoichiometry. Journal of Plankton Research 32:119-137.

Flynn, K. J., D. K. Stoecker, A. Mitra, J. A. Raven, P. M. Glibert, P. J. Hansen, E. Granéli, et al. 2013. Misuse of the phytoplankton-zooplankton dichotomy: The need to assign organisms as mixotrophs within plankton functional types. Journal of Plankton Research 35:3-11.

Geider, R. J., C. M. Moore, and O. N. Ross. 2009. The role of cost-benefit analysis in models of phytoplankton growth and acclimation. Plant Ecology \& Diversity 2:165178.

Gianuca, A. T., J. H. Pantel, and L. De Meester. 2016. Disentangling the effect of body size and phylogenetic distances on zooplankton top-down control of algae.

Proceedings of the Royal Society B: Biological Sciences 283:20160487.

Hansen, B., P. K. Bjørnsen, and P. J. Hansen. 1994. The size ratio between planktonic predators and their prey. Limnology and Oceanography 39:395-403.

Hansen, P. J., P. K. Bjørnsen, and B. W. Hansen. 1997. Zooplankton grazing and growth: Scaling within the $2-2,000-\mu \mathrm{m}$ body size range. Limnology and Oceanography 42:687-704. 
Hartmann, M., C. Grob, G. A. Tarran, A. P. Martin, P. H. Burkill, and D. J. Scanlan. 2012. Mixotrophic basis of Atlantic oligotrophic ecosystems. Proceedings of the National Academy of Sciences 109:5756-5760.

Hessen, D. O., and E. van Donk. 1993. Morphological changes in Scenedesmus induced by substances released from Daphnia. Arch. Hydrobiol 127:129-140.

Hirst, A. G., and T. Kiørboe. 2002. Mortality of marine planktonic copepods: Global rates and patterns. Marine Ecology Progress Series 230:195-209.

Huete-Ortega, M., T. Rodríguez-Ramos, D. C. López-Sandoval, P. Cermeño, J. M. Blanco, R. L. Palomino, J. Rodríguez, et al. 2014. Distinct patterns in the size-scaling of abundance and metabolism in coastal and open-ocean phytoplankton communities. Marine Ecology Progress Series 515:61-71.

Hutchinson, G. E. 1961. the Paradox of the Plankton. The American Naturalist 95:137-145.

Irigoien, X. 2005. Phytoplankton blooms: a "loophole" in microzooplankton grazing impact? Journal of Plankton Research 27:313-321.

Jones, R. I. 2000. Mixotrophy in plantonic protists: an overview. Freshwater Biology 45:219-226.

Kiørboe, T. 1993. Turbulence, phytoplankton cell size, and the structure of pelagic food webs. Adv. Mar. Biol. 29:1-72.

Kiørboe, T. 2011. How zooplankton feed: Mechanisms, traits and trade-offs. Biological Reviews 86:311-339.

Kiørboe, T., and A. G. Hirst. 2014. Shifts in mass scaling of respiration, feeding, and growth rates across life-form transitions in marine pelagic organisms. The American naturalist 183:E118-E130.

Kiørboe, T., H. Kaas, B. Kruse, F. Møhlenberg, P. Tiselius, and G. Ertebjerg. 1990. The structure of the pelagic food web in relation to water column structure in the Skagerrak . Marine Ecology Progress Series 59:19-32.

Litchman, E. 2012. Phytoplankton. In J. H. B. and A. K.-B. R. M. Sibly, ed., Metabolic Ecology: A Scaling Approach (pp. 154-163). John Wiley \& Sons, Ltd, Chichester, UK.

Litchman, E., and C. A. Klausmeier. 2008. Trait-Based Community Ecology of Phytoplankton. Annual Review of Ecology, Evolution, and Systematics 39:615-639.

Litchman, E., C. A. Klausmeier, O. M. Schofield, and P. G. Falkowski. 2007. The role of functional traits and trade-offs in structuring phytoplankton communities: Scaling from cellular to ecosystem level. Ecology Letters 10:1170-1181.

Lohier, T., F. Jabot, D. Meziane, B. Shipley, P. B. Reich, and G. Deffuant. 2014.

Explaining ontogenetic shifts in root-shoot scaling with transient dynamics. Annals of 
Botany 114:513-524.

Long, J. D., G. W. Smalley, T. Barsby, J. T. Anderson, and M. E. Hay. 2007. Chemical cues induce consumer-specific defenses in a bloom-forming marine phytoplankton. Proceedings of the National Academy of Sciences of the United States of America 104:10512-10517.

Marañón, E., P. Cermeño, D. C. López-Sandoval, T. Rodríguez-Ramos, C. Sobrino, M. Huete-Ortega, J. M. Blanco, et al. 2013. Unimodal size scaling of phytoplankton growth and the size dependence of nutrient uptake and use. Ecology Letters 16:371379.

Marañón, E., P. Cermeno, J. Rodriguez, M. V. Zubkov, and R. P. Harris. 2007. Scaling of phytoplankton photosynthesis and cell size in the ocean. Limnology and Oceanography 52:2190-2198.

Moloney, C. L., and J. G. Field. 1989. General allometric equations for rates of nutrient uptake, ingestion, and respiration in plankton organisms. Limnology and Oceanography 34:1290-1299.

Morel, A., and A. Bricaud. 1981. Theoretical results concerning light absorption in a discrete medium, and application to specific absorption of phytoplankton. Deep Sea Research 28:1375-1393.

Munk, W. H., and G. A. Riley. 1952. Absorption of nutrients by aquatic plants. Journal of Marine Research 11:215-240.

Poorter, H., K. J. Niklas, P. B. Reich, J. Oleksyn, P. Poot, and L. Mommer. 2011. Biomass allocation to leaves, stems and roots: meta-analysis of interspecific variation and environmental control. New Phytologist 193:30-50.

Raven, J. A. 1984. A cost-benefit analysis of photon absorption by photosynthetic unicells. New Phytologist 98:593-625.

Raven, J. A. 1997. Phagotrophy in phototrophs. Limnology and Oceanography 42:198-205.

Redfield, A. C. 1958. The biological control of chemical factors in the environment. American Scientist 46:205-221.

Shimeta, J. 1993. Diffusional encounter of submicrometer particles and small cells by suspension feeders. Limnology and Oceanography 38:456-465.

Shuter, B. 1979. A Model of Physiological Adaptation in Unicellular Algae. Journal of Theoretical Biology 78:519-552.

Sicko-Goad, L. M., C. L. Schelske, and E. F. Stoermer. 1984. Estimation of intracellular carbon and silica content of diatoms from natural assemblages using morphometric techniques. Limnology and Oceanography 29:1170-1178. 
Smith, S. L., A. Merico, K. W. Wirtz, and M. Pahlow. 2014. Leaving misleading legacies behind in plankton ecosystem modelling. Journal of Plankton Research 36:613-620.

Smith, S. L., M. Pahlow, A. Merico, and K. W. Wirtz. 2011. Optimality-based modeling of planktonic organisms. Limnology and Oceanography 56:2080-2094.

Stoecker, D. K. 1998. Conceptual models of mixotrophy in planktonic protists and some ecological and evolutionary implications. European Journal of Protistology 34:281-290.

Stramska, M. 2009. Particulate organic carbon in the global ocean derived from SeaWiFS ocean color. Deep-Sea Research Part I: Oceanographic Research Papers 56:1459-1470.

Taguchi, S. 1976. Relationship between photosynthesis and cell size of marine diatoms. Journal of Phycology 12:185-189.

Thingstad, T. F., L. Øvreås, J. K. Egge, T. Løvdal, and M. Heldal. 2005. Use of nonlimiting substrates to increase size; a generic strategy to simultaneously optimize uptake and minimize predation in pelagic osmotrophs? Ecology Letters 8:675-682.

Troost, T. A., B. W. Kooi, and S. A. L. M. Kooijman. 2005. Ecological specialization of mixotrophic plankton in a mixed water column. The American naturalist 166:E45E61.

Våge, S., M. Castellani, J. Giske, and T. F. Thingstad. 2013. Successful strategies in size structured mixotrophic food webs. Aquatic Ecology 47:329-347.

Wang, X., Y. Wang, L. Ou, X. He, and D. Chen. 2015. Allocation Costs Associated with Induced Defense in Phaeocystis globosa (Prymnesiophyceae): the Effects of Nutrient Availability. Scientific Reports 5:10850.

Ward, B. A., S. Dutkiewicz, A. D. Barton, and M. J. Follows. 2011. Biophysical aspects of resource acquisition and competition in algal mixotrophs. The American naturalist 178:98-112.

Ward, B. A., S. Dutkiewicz, O. Jahn, and M. J. Follows. 2012. A size-structured foodweb model for the global ocean. Limnology and Oceanography 57:1877-1891.

Ward, B. A., and M. J. Follows. 2016. Marine mixotrophy increases trophic transfer efficiency, mean organism size, and vertical carbon flux. Proceedings of the National Academy of Sciences of the United States of America 113:2958-2963.

Westberry, T., M. J. Behrenfeld, D. A. Siegel, and E. Boss. 2008. Carbon-based primary productivity modeling with vertically resolved photoacclimation. Global Biogeochemical Cycles 22:1-18.

Zervoudaki, S., T. G. Nielsen, and J. Carstensen. 2009. Seasonal succession and composition of the zooplankton community along an eutrophication and salinity gradient exemplified by Danish waters. Journal of Plankton Research 31:1475-1492. 
Zhang, H., K. Wang, X. Xu, T. Song, Y. Xu, and F. Zeng. 2015. Biogeographical patterns of biomass allocation in leaves, stems, and roots in China's forests. Scientific Reports $5: 15997$.

Zhao, M., and S. W. Running. 2010. Drought-Induced Reduction in Global Terrestrial Net Primary Production from 2000 Through 2009. Science 329:940-943.

\section{References from the Appendixes}

Andersen, K. H., T. Berge, R. J. Goncalves, M. Hartvig, J. Heuschele, et al. 2016. Characteristic sizes of life in the oceans, from bacteria to whales. Annual Review of Marine Science 8:1-25.

Barton, A. D., A. J. Pershing, E. Litchman, N. R. Record, K. F. Edwards, Z. V. Finkel, T. Kiørboe, et al. 2013. The biogeography of marine plankton traits. Ecology Letters 16:522-534.

Berg, H.C. and Purcell, E.M., 1977. Physics of Chemoreception. Biophysical Journal 20(2),193-219.

Edwards, K. F., M. K. Thomas, C. a. Klausmeier, and E. Litchman. 2012. Allometric scaling and taxonomic variation in nutrient utilization traits and maximum growth rate of phytoplankton. Limnology and Oceanography 57:554-566.

Fiksen, $\emptyset .$, M. J. Follows, and D. L. Aksnes. 2013. Trait-based models of nutrient uptake in microbes extend the Michaelis-Menten framework. Limnology and Oceanography 58:193-202.

Hansen, P. J., P. K. Bjørnsen, and B. W. Hansen. 1997. Zooplankton grazing and growth: Scaling within the $2-2,000-\mu \mathrm{m}$ body size range. Limnology and Oceanography 42:687-704.

Kiørboe, T. 2011. How zooplankton feed: Mechanisms, traits and trade-offs. Biological Reviews 86:311-339.

Marañón, E., P. Cermeño, D. C. López-Sandoval, T. Rodríguez-Ramos, C. Sobrino, M. Huete-Ortega, J. M. Blanco, et al. 2013. Unimodal size scaling of phytoplankton growth and the size dependence of nutrient uptake and use. Ecology Letters 16:371379.

Moloney, C.L. and Field, J.G., 1989. General allometric equations for rates of nutrient uptake, ingestion, and respiration in plankton organisms. Limnology and Oceanography 34,1290-1299.

Raven, J. A. 1997. Phagotrophy in phototrophs. Limnology and Oceanography 42:198-205. 
Smith, S. L., A. Merico, K. W. Wirtz, and M. Pahlow. 2014. Leaving misleading legacies behind in plankton ecosystem modelling. Journal of Plankton Research 36:613-620.

Taguchi, S., 1976. Relationship between photosynthesis and cell size of marine diatoms. Journal of Phycology 12,185-189.

Ward, B. A., S. Dutkiewicz, O. Jahn, and M. J. Follows. 2012. A size-structured foodweb model for the global ocean. Limnology and Oceanography 57:1877-1891. 
Table 1. Central symbols and general parameters. Index $i$ refers to light $(L)$ measured in units of $\mathrm{W} \mathrm{m}^{-2}$, nutrients $(N)$ in units of $\mu \mathrm{gN}$ liter $^{-1}$ or food $(F)$ in units of $\mu \mathrm{gC}$ liter

${ }^{1}$. Ranges for the variation of the parameters around the calibrated values are also given.

\begin{tabular}{llll} 
Symbol Name & Value and unit Range \\
\hline
\end{tabular}

$\boldsymbol{X}_{\boldsymbol{L}} \quad$ Light flux in the environment $\quad \mathrm{W} \mathrm{m}^{-2}$

$\boldsymbol{X}_{\boldsymbol{N}} \quad$ Concentration of nutrients in the $\quad \mu \mathrm{gN}$ liter $^{-1}$ environment

$\boldsymbol{X}_{\boldsymbol{F}} \quad$ Concentration of food in the $\quad \mu \mathrm{gC}$ liter $^{-1}$ environment

$\boldsymbol{A}_{\boldsymbol{L}} \quad$ Affinity for light. Value determined $\quad \mu \mathrm{gC}\left(\mathrm{Wm}^{-2}\right)^{-1} \mathrm{day}^{-1}$ by traits

$\boldsymbol{A}_{\boldsymbol{N}} \quad$ Affinity for nutrients. Value $\quad$ liter day ${ }^{-1}$ determined by traits

$\boldsymbol{A}_{\boldsymbol{F}} \quad$ Affinity for food. Value determined liter day ${ }^{-1}$ by traits

Maximum uptake rates

$M_{i}$

$\mu \mathrm{gC}$ day $^{-1}$ or

$\mu \mathrm{gN} \mathrm{day}^{-1}$

$\boldsymbol{J}_{\boldsymbol{i}} \quad$ Flux of assimilated substance or respiration

$\mu \mathrm{gC}$ day $^{-1}$ or

$\mu \mathrm{gN}$ day $^{-1}$

$\boldsymbol{\phi}_{\boldsymbol{i}} \quad$ Investment traits

Variable $\left(\mu \mathrm{gC} \mu \mathrm{gC}^{-1}\right)$

V Structural mass

Variable $(\mu \mathrm{gC})$

$\boldsymbol{a}_{\boldsymbol{L}} \quad$ Affinity per investment in phototrophy

$10 \mu \mathrm{gC}$ day $^{-1}$

$$
\left(\mathrm{Wm}^{-2}\right)^{-1} \mu \mathrm{gC}^{-1}
$$

$\boldsymbol{a}_{\boldsymbol{N}} \quad$ Affinity per investment for nutrients

0.6 liter day ${ }^{-1} \mu \mathrm{gC}^{-1}$

$\boldsymbol{a}_{\boldsymbol{F}} \quad$ Affinity per investment for food

0.06 liter day $^{-1} \mu \mathrm{gC}^{-1}$ 


\begin{tabular}{|c|c|c|}
\hline$m_{L}$ & $\begin{array}{l}\text { Max. uptake rate per investment in } \\
\text { phototrophy }\end{array}$ & 1.6 day $^{-1}$ \\
\hline $\boldsymbol{m}_{N}$ & $\begin{array}{l}\text { Max. uptake rate per investment for } \\
\text { nutrients }\end{array}$ & $1 \mu \mathrm{gN}$ day $^{-1} \mu \mathrm{gC}^{-1}$ \\
\hline$m_{F}$ & $\begin{array}{l}\text { Max. uptake rate per investment for } \\
\text { food }\end{array}$ & 15 day $^{-1}$ \\
\hline & Maximum light affinity & \\
\hline$c_{L}$ & & $0.01 \mu \mathrm{gC} \mathrm{day}^{-1}$ \\
\hline & Maximum affinity for nutrient & $\left(\mathrm{Wm}^{-2}\right)^{-1}\left(\mu \mathrm{gC}^{2 / 3}\right)^{-1}$ \\
\hline$c_{N}$ & & 0.000162 liter day ${ }^{-1}$ \\
\hline & Maximum affinity for food & $\left(\mu \mathrm{gC}^{1 / 3}\right)^{-1}$ \\
\hline$c_{F}$ & & $\begin{array}{l}0.04 \text { liter day }{ }^{-1} \\
(\mu \mathrm{gC})^{-1}\end{array}$ \\
\hline$R_{L}$ & Cost of photosynthesis & $0.08 \mu \mathrm{gC} \mu \mathrm{gC}^{-1}$ \\
\hline$R_{N}$ & Cost of nutrient uptake & $0.0141 \mu \mathrm{gC} \mu \mathrm{gN}^{-1}$ \\
\hline $\boldsymbol{R}_{F}$ & Cost of food uptake & $0.08 \mu \mathrm{gC} \mu \mathrm{gC}^{-1}$ \\
\hline$r_{0}$ & Maintenance cost of structure & $0.04 \mathrm{day}^{-1}$ \\
\hline$r_{L}$ & Maintenance cost of light harvesting & 0.18 day $^{-1}$ \\
\hline$r_{N}$ & Maintenance cost of nutrient uptake & $0.06 \mathrm{day}^{-1}$ \\
\hline$r_{F}$ & Maintenance of phagotrophy & 0.04 day $^{-1}$ \\
\hline$\phi_{L}$ & Investment in photosynthesis & $0.5 \mu \mathrm{gC} \mu \mathrm{gC}^{-1}$ \\
\hline$\phi_{N}$ & Investment in nitrate harvest & $0.2 \mu \mathrm{gC} \mu \mathrm{gC}^{-1}$ \\
\hline$\phi_{F}$ & Investment in phagotrophy & $0.2 \mu \mathrm{gC} \mu \mathrm{gC}^{-1}$ \\
\hline$\delta$ & Mortality constant & $0.008 \mu \mathrm{gC}^{1 / 4} \mathrm{day}^{-1}$ \\
\hline
\end{tabular}




$\begin{array}{cll}\boldsymbol{Q}_{\boldsymbol{C N}} & \mathrm{C} / \mathrm{N} \text { ratio in food and in the cell } & 5.68 \mu \mathrm{gC} \mu \mathrm{gN}^{-1} \\ \boldsymbol{\rho} & \begin{array}{l}\text { Fraction of down-regulation of } \\ \text { nutrient }\end{array} & --\end{array}$




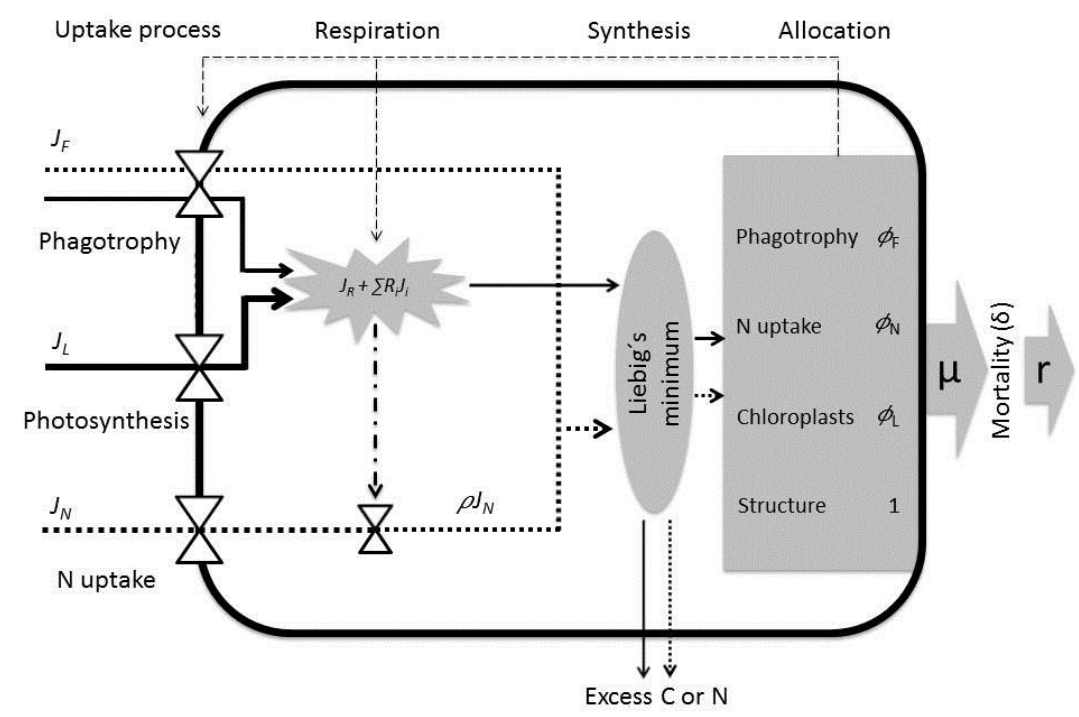

Figure 1. Schematic representation of the model showing how fluxes of carbon (solid lines) and nitrate (dotted lines) are respired (explosion symbol) and stoichiometrically combined (gray ellipse) to harvesting traits $\left(\phi_{i}\right)$ and structure (gray rectangle). Big white triangles represent the functional responses for the uptake mechanisms. The small white triangle represents the down-regulation of nitrate uptake (dashed-dotted line) due to the limitation of carbon from the photosynthetic pathway, i.e. nitrate harvest activity depends on energy from sunlight. The actual nutrient uptake is reduced by a factor $\rho$ of the potential nutrient uptake $J_{N}$ when there is insufficient carbon to pay the respiratory costs of uptake (eq. [9]). Respiration (eq. [8]) includes the basal respiratory costs of maintenance of all organelles corresponding to resource uptakes and structure, $J_{R}$, and the respiratory cost for uptake and mobilization for synthesis -- the latter formulated as a fraction $R_{j}$ of the uptake, $\sum R_{j} J_{i}$. The synthesis of biomass from the remaining available carbon and nutrients following Liebig's law of the minimum (gray ellipse) constrained by the Redfield ratio (mass C: $\mathrm{N}$ ratio = 5.68; Redfield, 1958). In this process a proportion of the assimilated carbon or nutrient may be lost as excess resources. Thin dashed lines illustrate how the resource allocation into traits and structure regulates uptake affinities and respiratory costs. The population growth rate $(r)$ can be obtained by substracting predation mortality $(\delta)$ from the mass specific synthesis rate $(\mu)$. See Table 1 for further explanation of the parameters. 

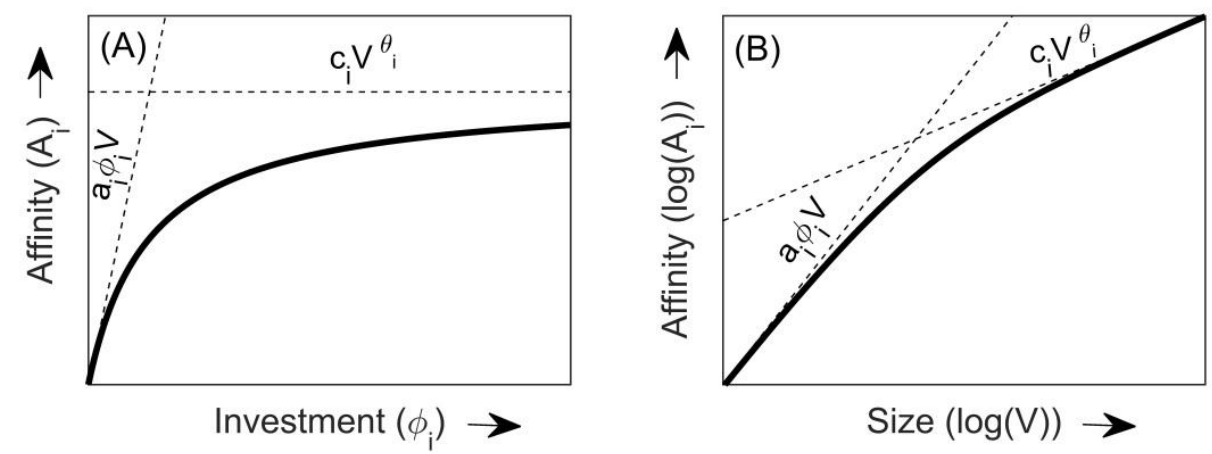

Figure 2. Dependence of affinity $\left(A_{i}\right)$ on investment $\left(\phi_{i}\right)$ and cell size $(V)$, according to equation (3). (A) Investments have diminishing returns described by the same mathematical equation as a functional response type II. (B) Affinity changes from scaling proportionally with cell size $(V)$ for smaller cells to being proportional to $V^{\theta_{i}}$ for larger cells. 

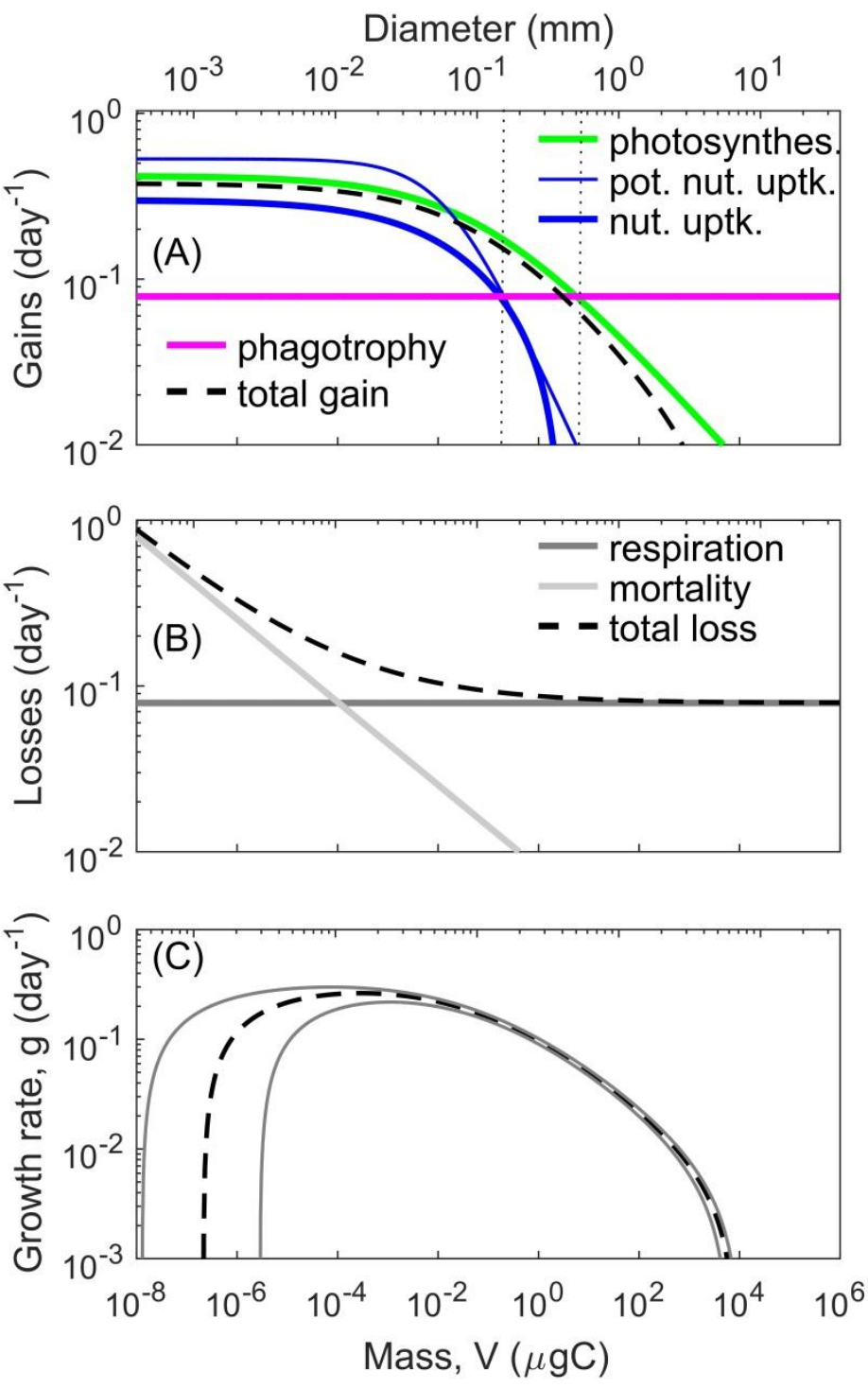

Figure 3. Size specific gains and losses and population growth rate as a function of cell size for a generalist mixotroph with fixed investments in light harvesting $\left(\phi_{L}=\right.$ $0.5)$, uptake of dissolved nutrients $\left(\phi_{N}=0.2\right)$, and phagotrophy $\left(\phi_{F}=0.2\right)$. (A) Specific uptake fluxes $\left(J_{i} / V_{t o t} ; J_{i}\right.$ from eq. [2], $V_{t o t}$ from eq. [1]) for the three resource acquisition modes: actual diffusive uptake of dissolved inorganic nutrient $\left(\mathrm{Q}_{\mathrm{CN}} \rho J_{N} / V_{\text {tot }}\right.$, thick blue $)$, given as the potential nutrient uptake $\left(\mathrm{Q}_{\mathrm{CN}} J_{N} / V_{\text {tot }}\right.$, thin blue), down-regulated by the factor $\rho$ (eq. [9]) with uptake of carbon through photosynthesis $\left(J_{L} / V_{t o t}\right.$, green) and food uptake through phagotrophy $\left(J_{F} / V_{\text {tot }}\right.$, magenta), and total gain (rate of biomass synthesis $J_{\text {tot }} / V_{\text {tot }}$ from eq. [10]; dashed black). Vertical dotted lines indicate transitions between different profitable nutritional modes; see text. (B) Specific loss due to respiration $\left(J_{R} / V_{\text {tot }}\right.$; eq. [8]; dark gray), due to mortality ( $\delta V^{-1 / 4}$; light gray), and the total specific loss $\left(J_{R} / V_{\text {tot }}+\right.$ $\delta V^{-1 / 4}$; dashed black). (C) Subtracting the total specific loss from the total specific gain gives the population growth rate (eq. [12]; dashed black), shown also for mortalities $\left(\mu_{P}\right) 50 \%$ higher or lower (thin black). Resource concentrations are: light intensity $X_{L}=33 \mathrm{~W} \mathrm{~m}^{-2}$, nutrients $X_{N}=66 \mu \mathrm{gN} \mathrm{liter}{ }^{-1}$, and food $X_{F}=17 \mu \mathrm{gC} \mathrm{liter}{ }^{-1}$. Other parameter values are given in Table 1. Bottom $x$-axes in each panel correspond to mass of organisms $(\mu \mathrm{gC})$ whereas top $x$-axes correspond to diameter $(\mathrm{mm})$. 


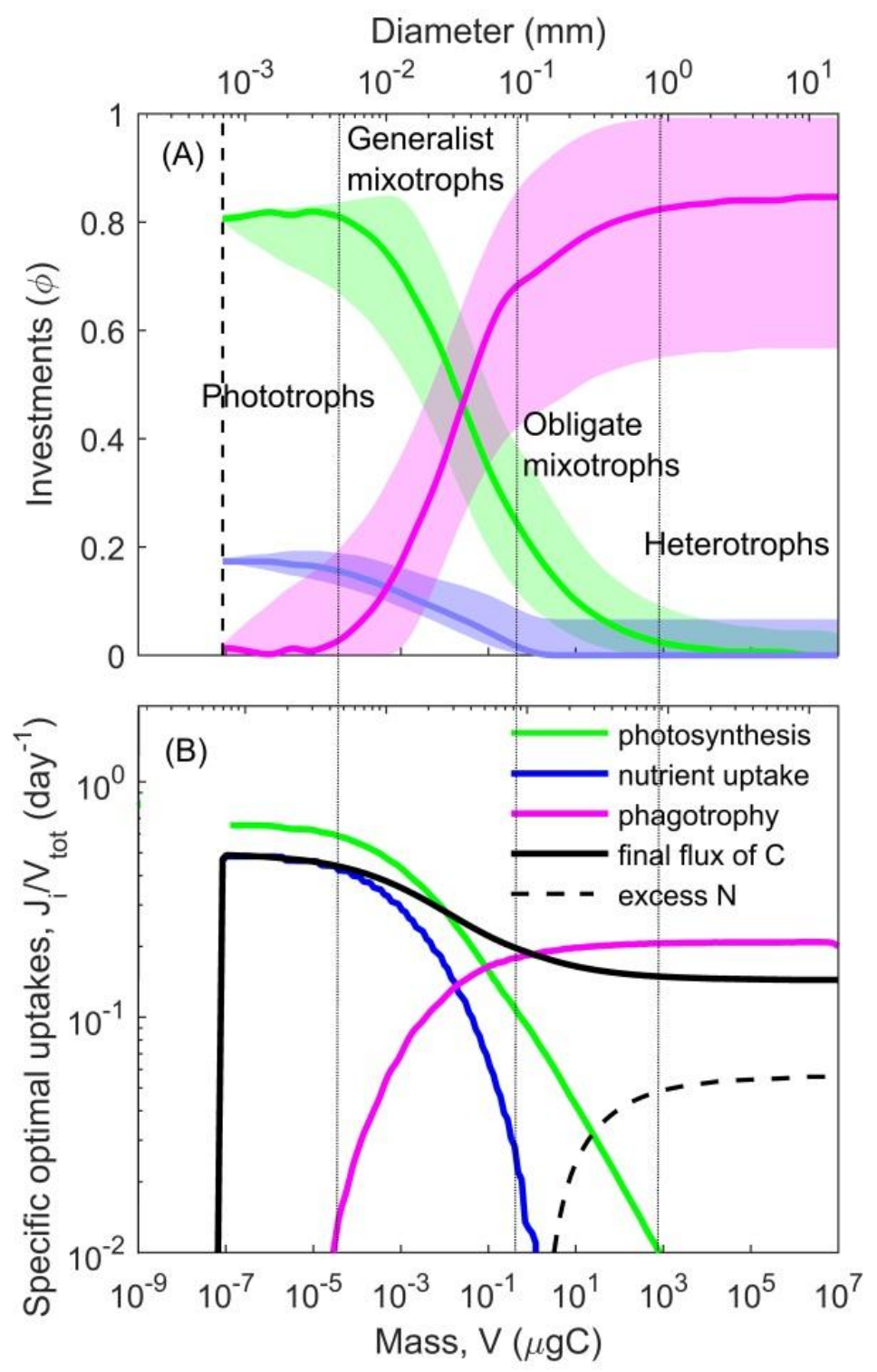

Figure 4. (A) Optimal investments (yielding highest population growth rate) in phototrophy $\phi_{L}^{*}$ (green), nutrient uptake $\phi_{N}^{*}$ (blue) and phagotrophy $\phi_{F}^{*}$ (magenta) as a function of cell size $(V)$ in a constant environment. Shaded areas represent the ranges of trait values giving growth rates within $95 \%$ of optimal growth rates. To the left of the vertical dashed line, growth rate is negative. Vertical dotted lines indicate transitions between different trophic strategies (see text): phototrophs mainly invest in photosynthesis and nutrient uptake and not in phagotrophy; generalist mixotrophs invest in all three traits; obligate mixotrophs invest only in phagotrophy; heterotrophs invest only in phagotrophy. (B) Mass specific uptake rates corresponding to optimal investments (photosynthesis: $J_{L} / V_{t o t}$, nutrient uptake: $Q_{\mathrm{CN}} J_{N} / V_{t o t}$, phagotrophy: $J_{F} / V_{\text {tot }}$, final flux of carbon: $\left.J_{\text {tot }} / V_{\text {tot }}\right)$. Excretion of excess $\mathrm{N}\left(\max \left(0,\left(Q_{\mathrm{CN}} \rho J_{N}+\right.\right.\right.$ $\left.\left.J_{F}-J_{t o t}\right) / V_{t o t}\right)$ day $^{-1}$ ) is marked by the dashed line. Resource concentrations are same as in fig. 3 and parameter values are given in Table 1. Bottom X-axes correspond to mass of organisms ( $\mu \mathrm{gC})$ whereas top $\mathrm{x}$-axes correspond to diameter $(\mathrm{mm})$. 

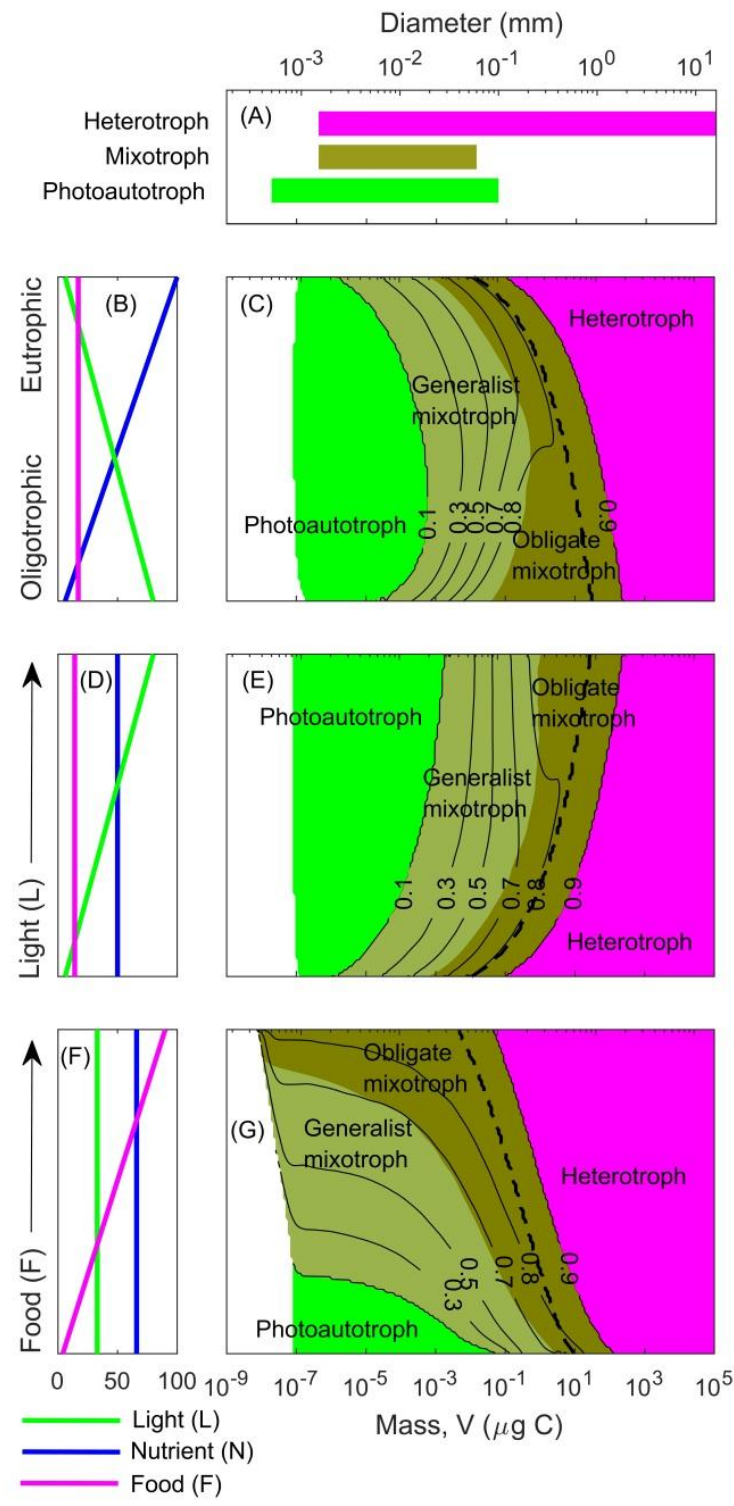

Figure 5. Optimal trophic strategies under varying resource concentrations. (A) Observed size ranges of heterotrophs (magenta), mixotrophs (army green) and photoautotrophs (light green) (from Andersen et al. 2016). (B) Variations in nutrient $\left(X_{N} ; \mu \mathrm{gN}\right.$ liter $\left.^{-1}\right)$ and light $\left(X_{L} ; \mathrm{W} \mathrm{m}{ }^{-2}\right)$ captures scenarios from oligotrophic to eutrophic environments. (D) Variations in light $\left(X_{L} ; \mathrm{W} \mathrm{m}^{-2}\right)$. (F) Variations in food concentration $\left(X_{F} ; \mu \mathrm{gC}\right.$ liter $\left.^{-1}\right)$. $(\mathrm{C}, \mathrm{E}, \mathrm{G})$ Transitions between the four trophic strategies delineated in fig. 4: pure photoautotrophs (light green), generalist mixotrophs (light army green), obligate mixotrophs (dark army green), and heterotrophs (magenta). Parameter values are given in Table 1. Bottom x-axes of A, $\mathrm{C}, \mathrm{E}$ and $\mathrm{G}$ show mass of organisms $(\mu \mathrm{gC})$ while top $\mathrm{x}$-axes correspond to diameter $(\mathrm{mm})$. 

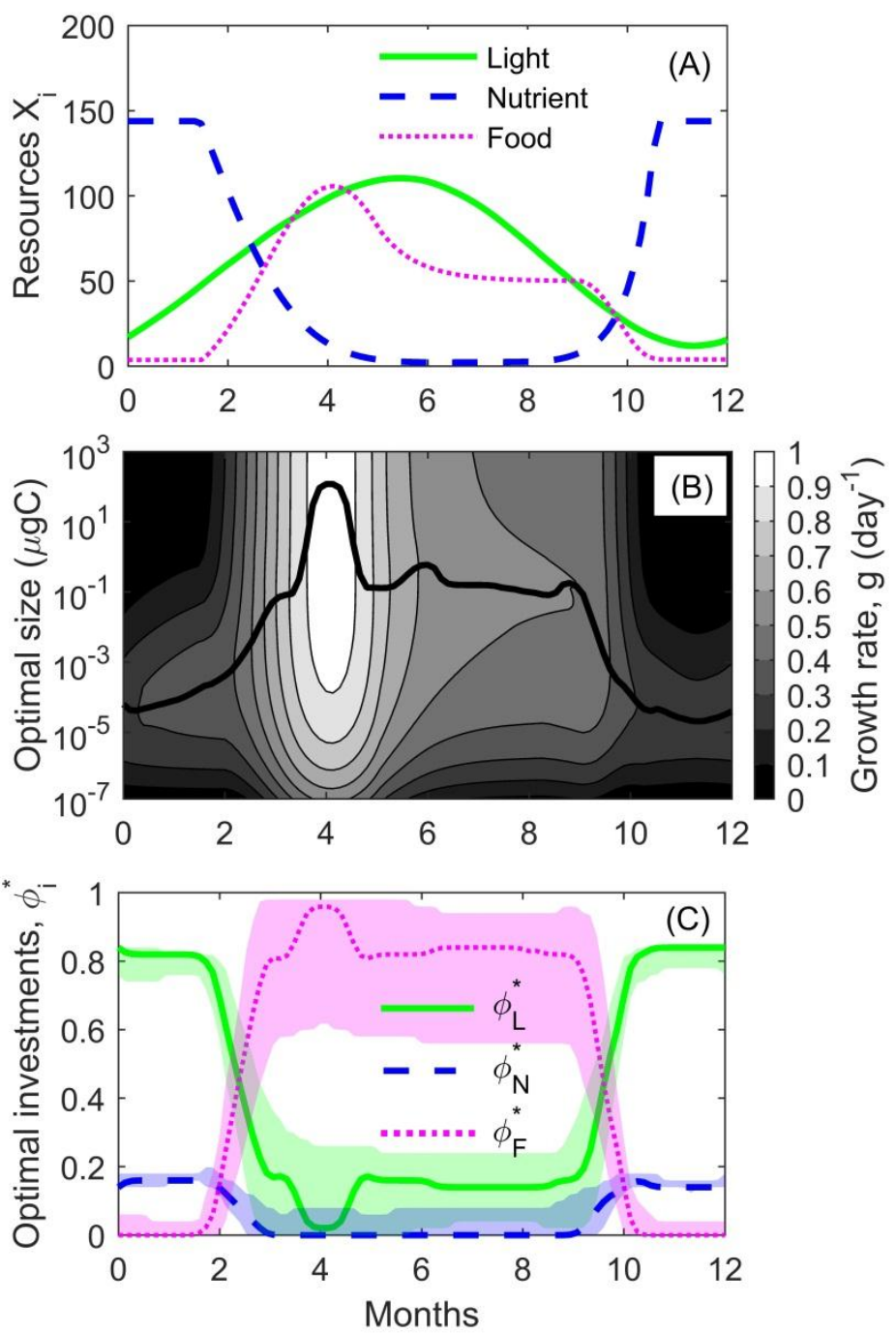

Figure 6. Seasonal succession in surface waters of a high-latitude plankton community. (A) Assumed seasonal variations in light $X_{L}\left(\mathrm{~W} \mathrm{~m}^{-2}\right)$ (green solid line), nitrate $X_{\mathrm{N}}\left(\mu \mathrm{gN}\right.$ liter $\left.{ }^{-1}\right)$ (blue dashed line) and prey $X_{F}\left(\mu \mathrm{gC}\right.$ liter $\left.^{-1}\right)$ (magenta dotted line). (B) Optimal sizes having optimal population growth rates (thick black line) and growth rates (shaded) with values given by the color bar at different size ranges with seasons. (C) The optimal investments (phototrophy $\phi_{L}^{*}$ (green), nutrient uptake $\phi_{N}^{*}$ (blue) and phagotrophy $\phi_{F}^{*}$ (magenta)) throughout the season illustrates the succession of strategies. Parameter values are given in Table 1. 

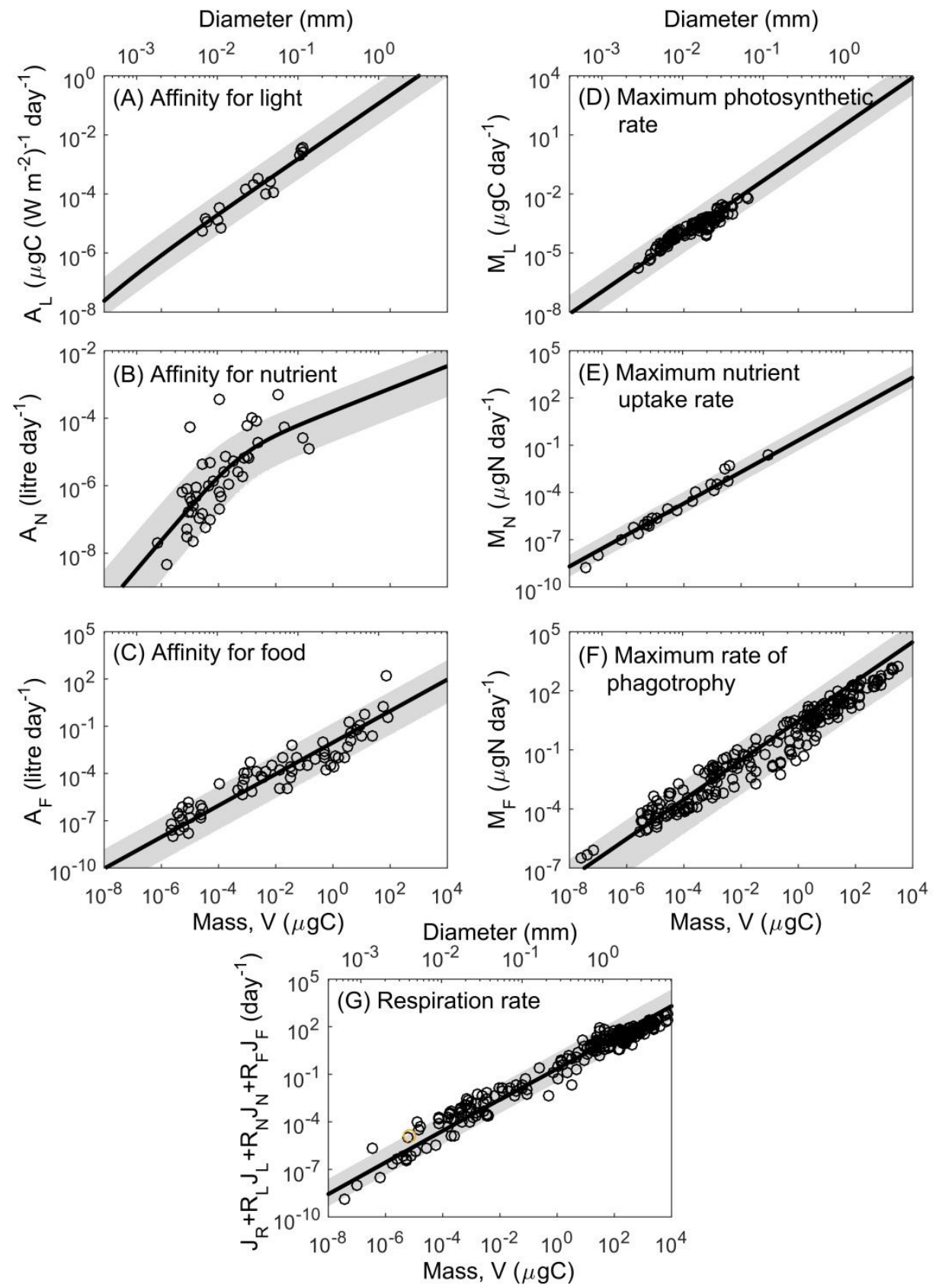

Figure C1. Affinities for light $A_{L}(\mathrm{~A})$, nutrients $A_{N}(\mathrm{~B})$ and food $A_{F}(\mathrm{C})$, maximum uptake rates of light $M_{L}(\mathrm{D})$, nutrient $M_{N}(\mathrm{E})$ and food $M_{F}(\mathrm{~F})$, and respiration rate $J_{R}+\sum R_{i} J_{i}(\mathrm{G})$ as a function of cell size. Open squares represent data points (sources are mentioned below) whereas solid lines represent affinities given by Eqs. (4-6) for the parameters given in Table 1 . The shaded regions are derived from simulations with random parameters within the ranges in Table 1. Data sources: affinity for light: Taguchi (1976); affinity for nutrient: Edwards et al. (2012); affinity for food: Kiørboe (2011); maximum photosynthetic rate: Ward et al. (2012); maximum nutrient uptake rate: Marañón et al. (2013) and Moloney \& Field (1989); maximum rate of phagotrophy: Moloney \& Field (1989) and Hansen et al. (1997); respiration rate: Moloney \& Field (1989) and Marañón et al. (2013). The corresponding resource concentrations (light, nutrient and food) during the calibration of parameters are $X_{L}=55 \mathrm{~W} \mathrm{~m}^{-2}, X_{N}=70 \mu \mathrm{gN}$ liter $^{-1}$, and $X_{F}=80 \mu \mathrm{gC} \mathrm{liter}^{-1}$, respectively, assuming non-limiting resource concentrations in each case. Bottom $\mathrm{X}$-axes 
correspond to mass of organisms $(\mu \mathrm{gC})$ whereas top $\mathrm{x}$-axes correspond to diameter $(\mathrm{mm})$.
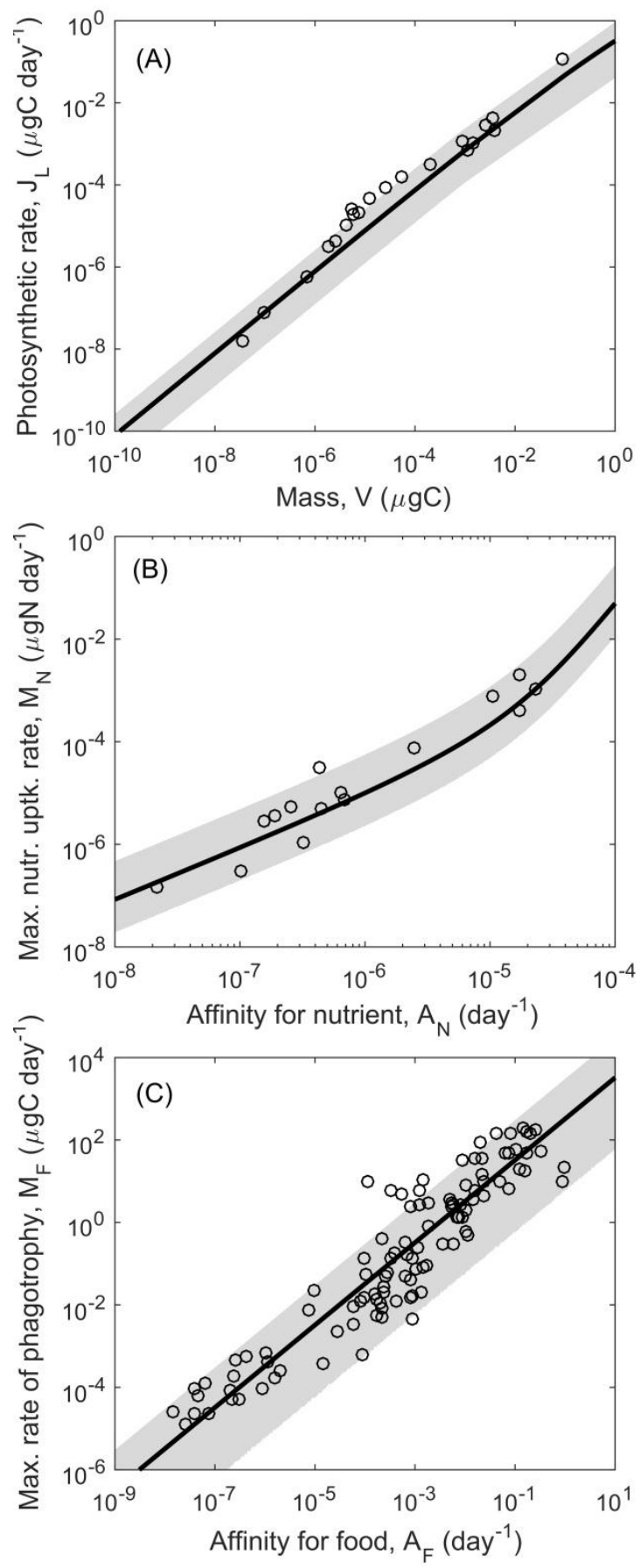

Figure C2. (A) Plot of actual photosynthetic rate $\left(J_{L}\right)$ as a function of cell size $(V)$ given by equation (2). Model outcome (solid line) vs. data (open circles; Marañón et al. (2013)). (B) Maximum nutrient uptake $\left(M_{N}\right)$ rate vs. affinity $\left(A_{N}\right)$ for nutrients from equation (5) (line) and data (circles; Smith et al. (2014)). (C) Maximum rate of phagotrophy $\left(M_{F}\right)$ vs. affinity $\left(A_{F}\right)$ for food from equation (6) (solid line) and data (open circles; Hansen et al. (1997)). The light, nutrient and food concentrations are 
the same as in fig. $\mathrm{C} 1$. The shaded regions are from simulations with random parameters drawn within the ranges in Table 1. 